Review Article

\title{
Zirconium-89 Labeled Antibodies: A New Tool for Molecular Imaging in Cancer Patients
}

\author{
Floor C. J. van de Watering, ${ }^{1}$ Mark Rijpkema, ${ }^{1}$ Lars Perk, ${ }^{2}$ \\ Ulrich Brinkmann, ${ }^{3}$ Wim J. G. Oyen, ${ }^{1}$ and Otto C. Boerman ${ }^{1}$ \\ ${ }^{1}$ Department of Radiology and Nuclear Medicine, Radboud University Medical Center, Geert Grooteplein Zuid 10, \\ 6525 GA, Nijmegen, The Netherlands \\ ${ }^{2}$ Radboud Translational Medicine B.V., Reinier Postlaan 2, 6525 GC, Nijmegen, The Netherlands \\ ${ }^{3}$ Roche Pharma Research \& Early Development, Large Molecule Research, Nonnenwald 2, 82377 Penzberg, Germany
}

Correspondence should be addressed to Otto C. Boerman; otto.boerman@radboudumc.nl

Received 14 March 2014; Accepted 23 April 2014; Published 28 May 2014

Academic Editor: Roland Haubner

Copyright (c) 2014 Floor C. J. van de Watering et al. This is an open access article distributed under the Creative Commons Attribution License, which permits unrestricted use, distribution, and reproduction in any medium, provided the original work is properly cited.

\begin{abstract}
Antibody based positron emission tomography (immuno-PET) imaging is of increasing importance to visualize and characterize tumor lesions. Additionally, it can be used to identify patients who may benefit from a particular therapy and monitor the therapy outcome. In recent years the field is focused on ${ }^{89} \mathrm{Zr}$, a radiometal with near ideal physical and chemical properties for immuno-PET. In this review we will discuss the production of ${ }^{89} \mathrm{Zr}$, the bioconjugation strategies, and applications in (pre-)clinical studies of ${ }^{89} \mathrm{Zr}$ based immuno-PET in oncology. To date, ${ }^{89} \mathrm{Zr}$-based PET imaging has been investigated in a wide variety of cancer-related targets. Moreover, clinical studies have shown the feasibility for ${ }^{89} \mathrm{Zr}$-based immuno-PET to predict and monitor treatment, which could be used to tailor treatment for the individual patient. Further research should be directed towards the development of standardized and robust conjugation methods and improved chelators to minimize the amount of released $\mathrm{Zr}^{4+}$ from the antibodies. Additionally, further validation of the imaging method is required. The ongoing development of new ${ }^{89} \mathrm{Zr}$-labeled antibodies directed against novel tumor targets is expected to expand applications of ${ }^{89} \mathrm{Zr}$-labeled immuno-PET to a valuable method in the medical imaging.
\end{abstract}

\section{Introduction}

Molecular biomarkers can be used to monitor, image, and measure biological processes at molecular or cellular level. Different types of biomarkers are known, including diagnostic, prognostic, and predictive biomarkers, or a combination of these [1]. Extensive research has been done on the development of molecular imaging biomarkers in the field of cancer. This has led to tools that can be used to visualize and characterize tumor lesions. An advantage of using molecular imaging agents is the noninvasive nature of these procedures, whereas in conventional methods a more invasive procedure is used (e.g., blood sample or biopsy). Various imaging modalities can be used for tumor visualization such as fluorescent imaging, magnetic resonance imaging (MRI) or radionuclide imaging with positron emission tomography (PET), or single photon emission computed tomography (SPECT). In most cases, the use of PET is preferred over SPECT since higher spatial resolution images can be obtained and images can be analyzed quantitatively more accurately with PET. Specific uptake of molecular biomarkers can be achieved using radiolabeled targeting agents such as antibodies, directed against tumor-associated antigens like epidermal growth factor receptor (EGFR) [2], human epidermal growth factor receptor 2 (HER2), and many others. The high specificity and affinity of radiolabeled antibodies make them attractive candidates as an imaging agent. For example, ${ }^{89} \mathrm{Zr}$-labeled antiHER 2 antibodies can be used to differentiate between HER2 ${ }^{+}$ and HER2 $2^{-}$tumors [3], also appreciating intra- and intertumoral heterogeneity. An additional application of radiolabeled antibodies is to identify patients who may benefit from a particular therapy and monitor therapy outcome based on the level of tumor-associated antigen expression [4]. However, the relative slow pharmacokinetics of intact antibodies 
$\left(t_{1 / 2}=3-4\right.$ days $)$ requires the use of radionuclides with long half-lives (e.g., ${ }^{111}$ In (2.8 days) for SPECT or ${ }^{89} \mathrm{Zr}$ (3.3 days) and ${ }^{124} \mathrm{I}$ (4.2 days) for PET [5]). For antibody based PET imaging (immune-PET) ${ }^{89} \mathrm{Zr}$ has several advantages: ${ }^{89} \mathrm{Zr}$ has a half-life of $78.4 \mathrm{~h}$ which matches the pharmacokinetics of antibodies and it has a relative low average positron energy of $395 \mathrm{keV}$, making it an ideal candidate for high resolution PET imaging of slow-accumulating biomolecules. In addition, ${ }^{89} \mathrm{Zr}$-based agents are safer to handle and more stable in vivo making them better candidates than ${ }^{124}$ I-based agents for clinical applications. Due to the numerous advantages of ${ }^{89} \mathrm{Zr}$-based immuno-PET, the field is progressing at a rapid and exciting pace. In this review, the potential of ${ }^{89} \mathrm{Zr}$-based immuno-PET in oncology will be reviewed. The production of ${ }^{89} \mathrm{Zr}$, the bioconjugation strategies, and applications in (pre-)clinical studies are discussed.

\section{Radiochemical Properties of ${ }^{89} \mathrm{Zr}$}

${ }^{89} \mathrm{Zr}$ decays (half-life of $78.4 \mathrm{~h}$ ) first via positron emission and electron capture to ${ }^{89 \mathrm{~m}} \mathrm{Y}$ (half-life of $15.7 \mathrm{~s}$ ) which in turn decays via gamma ray emission $(909 \mathrm{keV})$ to the stable ${ }^{89} \mathrm{Y}$. With its relatively low energy positrons (average energy $395 \mathrm{keV}){ }^{89} \mathrm{Zr}$ provides high resolution PET images. In addition, the energy disparity between the photons $(511 \mathrm{keV})$ and the gamma rays $(909 \mathrm{keV})$ prevents the latter from interfering with the detection of $511 \mathrm{keV}$ photons. In contrast, its halogen competitor, ${ }^{124} \mathrm{I}$, produces high energy photons of different energies (603 keV (63.0\%), $1691 \mathrm{keV}(10.9 \%)$, and $723 \mathrm{keV}$ (10.4\%) [6]) which may result in random and scatter coincidences and therefore in more background noise as compared to ${ }^{89} \mathrm{Zr}$. Hence, reconstruction of ${ }^{89} \mathrm{Zr}$-based PET scans is more straightforward to attain good image quality compared to ${ }^{124}$ I. Although ${ }^{89} \mathrm{Zr}$ has many advantages over other PET radionuclides, some essential shielding requirements during transport and handling of ${ }^{89} \mathrm{Zr}$ are needed (half-value layer of ${ }^{89} \mathrm{Zr}$ in lead is roughly $10 \mathrm{~mm}$ ). High energy and highly penetrating photons $(909 \mathrm{keV})$ are emitted during ${ }^{89} \mathrm{Zr}$ decay in high abundance.

\section{Production of ${ }^{89} \mathrm{Zr}$}

The first production of ${ }^{89} \mathrm{Zr}$ was done by Link et al. [7] by a $(p, n)$ nuclear reaction by bombarding ${ }^{89} \mathrm{Y}$ on $\mathrm{Y}$ foil with $13 \mathrm{MeV}$ protons [5]. The produced ${ }^{89} \mathrm{Zr}$ needed several purification steps and was obtained in $80 \%$ yield with radionuclidic purity exceeding 99\%. Nowadays, many medical centers are able to produce medical isotopes using low-energy cyclotrons that are capable of bombarding targets with protons of low energy $(<20 \mathrm{MeV})$. Therefore, the most common route to produce ${ }^{89} \mathrm{Zr}$ is via the ${ }^{89} \mathrm{Y}(\mathrm{p}, \mathrm{n}){ }^{89} \mathrm{Zr}$ reaction on commercially available ${ }^{89} \mathrm{Y}$ target foils. The above route will in general result in high yields (94-95\%) and high radionuclidic purities (>99\%). Competing nuclear reaction, like ( $\mathrm{p}, 2 \mathrm{n})$ reactions, can result in small amounts radionuclidic byproducts, such as ${ }^{88} \mathrm{Zr}$ and ${ }^{88} \mathrm{Y}$ [8]. Several separation and purification techniques with variable outcomes are used including anion exchange, cation exchange, and solvent extraction [9-11]. For synthesizing such radiopharmaceuticals for patients, automated units for a clean, fast, safe, and reproducible radionuclide synthesis according to good manufacturing practice (GMP) are necessary. Several groups have designed and built automated systems for ${ }^{89} \mathrm{Zr}[12,13]$. For example Wooten et al. [14] reported a custom-made system to safely and routinely produce ${ }^{89} \mathrm{Zr}$ with high radionuclidic purity $(>99.99 \%)$ and satisfactory effective specific activity $\left(5-353 \mathrm{mCi} \cdot \mu \mathrm{mol}^{-1}\right.$ $(0.01 \%-0.88 \%$ of theoretical specific activity)) based on previous developments in separation and purification techniques [9-11, 15].

\section{The Need for Efficient Chelators}

The release of ${ }^{89} \mathrm{Zr}^{4+}$ from the antibodies needs to be prevented, because the free radionuclide can accumulate in the mineral bone and can associate with plasma proteins. This leads to depositing significant doses to the bone marrow [16]. Therefore, an appropriate chelator system is necessary to minimize the disassociation of ${ }^{89} \mathrm{Zr}$ from the antibodies. Over the years, several chelators have been used with different success, such as diethylenetriaminepentaacetic acid (DTPA), ethylenediaminetetraacetic acid (EDTA), 1,4,7,10-tetraacetic acid (DOTA), and desferoxamine (DFO) [17]. The stability of Zr-DOTA, Zr-DTPA, and Zr-EDTA was found to be limited. The thermodynamic stability of Zr-DTPA is slightly higher than that of Zr-EDTA, most likely because DTPA coordinatively saturates the $\mathrm{Zr}^{4+}$, while EDTA requires exogenous water molecules [18]. DFO is the most prominent chelator of $\mathrm{Zr}^{4+}$. DFO is a hexadentate siderophore containing three hydroxamate groups for chelating metals and a primary amine tail for conjugation to a biomolecule (Figure 1). Besides a zirconium chelator, it is a chelating agent for several other metal ions [19]. It demonstrated good stability, releasing less than $0.2 \%$ of $\mathrm{Zr}^{4+}$ after $24 \mathrm{~h}$ in serum [20] and after seven days in serum still less than $2 \%$ demetallation occurs [21]. Several proof-of-principle preclinical studies have been conducted using DFO to label antibodies with ${ }^{89} \mathrm{Zr}$; however, the in vivo stability of this complex remains an issue, because free ${ }^{89} \mathrm{Zr}$ is observed in the bone dependent on the in vivo behavior of the antibody [22]. Several studies have attempted to improve the linkage between DFO and the antibody $[9,23]$, whereas others have focused on improving the chelate itself [24]. Eventually, a ligand that is both octadentate and oxygen-rich is believed to be the most stable $\mathrm{Zr}^{4+}$ chelator, since it would be able to incorporate all eight coordination sites of zirconium [22]. This novel high stability $\mathrm{Zr}^{4+}$ ligand would in theory minimize the uptake of liberated $\mathrm{Zr}^{4+}$ in the bone and other nontargeted tissues. To date, the design, synthesis, and the evaluation of such a $\mathrm{Zr}^{4+}$ chelate requires further research.

4.1. Conjugation of Antibodies with DFO. As DFO is currently the most promising chelator for ${ }^{89} \mathrm{Zr}^{4+}$, conjugation of antibodies with DFO will be discussed here in detail (Figure 1). Several methods are available to conjugate DFO based on 


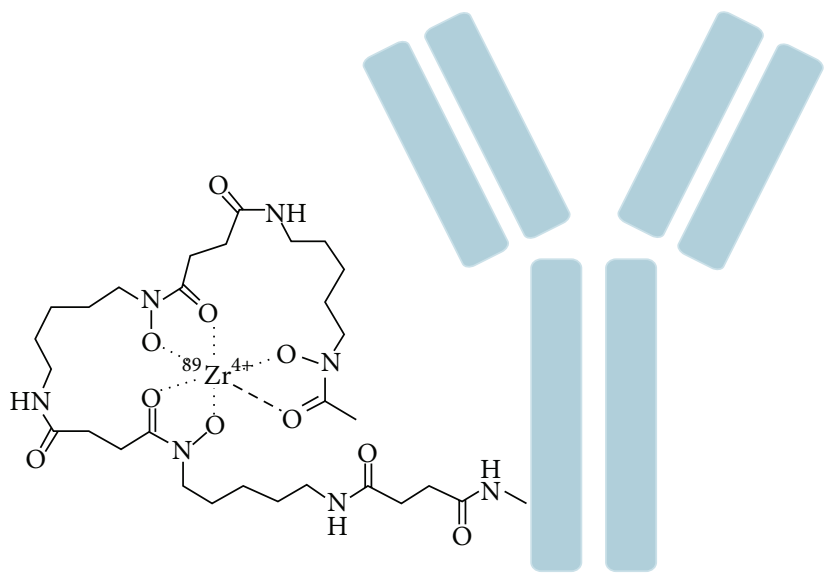

FIgURE 1: Schematic overview of ${ }^{89}$ Zr-labeled antibody using DFO as chelator.

the reaction of an activated bifunctional chelator with a lysine or cysteine residue of the antibody. The different conjugation techniques do not only have different conjugation efficiencies, but also affect the biodistribution of the radiolabeled antibody [22].

The earliest reports on conjugation of DFO to bioactive molecules is based on the addition of thiols to the amino group of DFO [20]. In this approach DFO was modified by $N$ succinimidyl-S-acetylthioacetate (SATA), resulting in an Sacetyl-protected thiol derivatized form of chelator. In parallel, maleimide moieties were introduced in the antibody by the reaction with 4 -( $N$-maleimidomethyl) cyclohexane carboxylic acid N-hydroxysuccinimide ester (SMCC). Next, the two formed compounds were combined and in the presence of hydroxylamine at physiological $\mathrm{pH}$ the DFO-antibody conjugate was formed. Following this early work, Verel et al. introduced a novel conjugation approach, which was based on an activated 2,3,5,6-tetrafluorophenol (TFP) chelate ester which can form a stable amide bond with the $\varepsilon$-amino-groups of the lysine residues of the monoclonal antibody ( $\mathrm{mAb}$ ) [9]. This laborious approach consisted of 5 steps which involve (i) the extension of DFO with succinyl anhydride, (ii) protection of side-reactions of the hydroxamate groups of the ligand by complexation with $\mathrm{Fe}^{3+}$, (iii) formation of activated TFP ester, (iv) conjugation of activated DFO-ester to the unmodified antibody, and (v) removal of $\mathrm{Fe}^{3+}$ from the chelator. Nowadays the most widely used method in preclinical ${ }^{89} \mathrm{Zr}$ based immuno-PET uses the conjugation strategy with $N$ succinimidyl-DFO, which addresses $\varepsilon$-amino groups of lysine side chains $[22,25-30]$. Since the $\mathrm{Zr}^{4+}$ field is rapidly growing and becoming more mainstream in the clinical setting, simple methods for DFO conjugation preferably using commercial available starting materials are essential. Perk et al. introduced a simplified method using a commercially available p-isothiocyanatobenzyl-DFO (DFO-Bz-NCS) chelate, which can be directly attached to the $\varepsilon$-aminogroups of the lysine residues of an antibody by forming a stable thiourea linkage [23]. Despite the fact that this method is simpler than the $N$-succinimidyl-DFO chemistry, it requires more expertise mainly because of the limited water solubility of the chelator precursor.
A limitation of the conjugation of DFO to antibodies is compromised immunoreactivity, because the chelator may interfere with the antigen-binding domain of the antibody, especially if there are lysines in or close to the complementarity determining regions of the antibody. To overcome these limitations site-specific strategies using engineered cysteine residues can be used in combination with thiol-reactive DFO derivatives such as bromoacetamido-desferrioxamine (DFO$\mathrm{Bac}$ ), iodoacetamido-desferrioxamine (DFO-Iac), and maleimidocyclohexyl-desferrioxamine (DFO-CHX-Mal) [31]. The radiolabeled antibodies using these thiol-reactive DFO derivatives were stable and showed similar characteristics as the lysine-linked complexes. Remarkably, no significant difference was observed between the immunoreactivity of the site-specific complex and the lysine-linked complexes.

Another novel conjugation approach for effective labeling of ${ }^{89} \mathrm{Zr}$ to antibodies is the use of click chemistry between an acetylene group and an azide. This approach might not significantly improve the targeting of tumors compared with DFObased conjugation strategies; however, with this approach it is possible to fully tailor the constructs. Furthermore, the modular system can be used for direct comparison of bioconjugates with different radiometals as the the chelatormodified antibodies are synthesized using identical ligation conditions resulting in similar immunoreactivity and chelator/antibody ratios [32]. Several studies have been reported on bioorthogonal click chemistry [32], Staudinger ligation [33], or catalyst-free click chemistry [34]. The click chemistry as specialized conjugation method is expected to expand the scope of ${ }^{89} \mathrm{Zr}$-based PET.

\section{Preclinical Studies with ${ }^{89} \mathrm{Zr}$}

Over the last years several ${ }^{89} \mathrm{Zr}$-labeled antibodies directed against different tumor types have been evaluated in preclinical studies (e.g., $[9,18,22,35,36]$; see Table 1). Here these developments of ${ }^{89} \mathrm{Zr}$-labeled antibodies in preclinical studies will be discussed based on their tumor target.

5.1. Targeting CD20. The glycosylated phosphoprotein, CD20, is expressed on the surface of B-cell lymphomas, hairy 
TABLE 1: Overview of the described preclinical and clinical studies using ${ }^{89} \mathrm{Zr}$-labeled antibodies.

\begin{tabular}{lcc}
\hline Target & Type of tumor & Targeting vector \\
\hline CD147 & Pancreas & $059-053$ \\
CD20* & Non-Hodgkin's lymphoma & ibritumomab tiuxetan \\
CD44v6* & Head and neck squamous cell carcinoma & Cetuximab \\
EGFR & Multiple & hRS7 \\
EGP-1 & Prostate & $\alpha$ GPC3 \\
GPC3 & Liver & Panitumunmab \\
HER1 & Colorectal & Trastuzumab \\
HER2 & Breast and ovarian & R1507 \\
IGF-1R & Triple negative breast cancer & DN30 \\
MET & Renal cell carcinoma & cG250 \\
MN/CA IX & Prostate & 7 E11 \\
PSMA & Liver & RO5323441 \\
PIGF & Head and neck squamous cell carcinoma and gastric & Bevacizumab \\
VEGF & Breast, head, and neck squamous cell carcinoma and ovarian & \\
\hline
\end{tabular}

${ }^{*}$ Targets evaluated in clinical studies.

leukemia, B-cell chronic lymphocytic leukemia, and melanoma cells. ${ }^{89} \mathrm{Zr}$-labeled antibodies directed against CD20 might be useful to measure and monitor the therapeutic effect of non-Hodgkin's lymphoma (NHL) therapy [18, 37]. The ${ }^{89} \mathrm{Zr}$-Desferrioxamine-rituximab, an antibody directed against CD20, specifically targeted the human CD20 antigen in a humanized CD20-expressing transgenic mouse model (huCD20TM). ${ }^{90}$ Y-labeled anti-CD20 mAb ibritumomab tiuxetan (Zevalin) is approved for treatment of patients with relapsed and refractory NHL. In a pilot study, ${ }^{89} \mathrm{Zr}$-labeled ibritumomab tiuxetan was shown to have a nearly identical biodistribution compared to ${ }^{90}$ Y-labeled counterpart [18]. This indicated that a scout scan with ${ }^{89} \mathrm{Zr}$-ibritumomab immuno-PET can be used to assess, predict, and quantify the biodistribution of ${ }^{90} \mathrm{Y}$-ibritumomab tiuxetan.

5.2. Targeting CD44. The cell-surface glycoprotein, CD44, is involved in many biological processes including adhesion of cells to extracellular matrix proteins, lymphocyte-endothelial cell interactions, metastasis formation, migration of cells, and $\mathrm{T}$ cell activation/adherence [38]. The v6 splice variant of CD44 is involved in tumorigenesis, tumor cell invasion, and metastasis and is expressed preferentially in squamous cell carcinomas [39]. Preclinical studies using ${ }^{89} \mathrm{Zr}$-labeled antiCD44v6 chimeric monoclonal antibody cU36 demonstrated that the tracer was able to detect small tumors in nude mice with HNSCC xenografts $[9,40]$. In addition, it was reported that ${ }^{89} \mathrm{Zr}$-cU36 PET imaging was a suitable candidate for scouting of therapeutic doses of ${ }^{90} \mathrm{Y}-\mathrm{cU} 36[40,41]$. Recently, evaluation of ${ }^{89} \mathrm{Zr}$-RG7356, an antibody directed against the constant part of CD44, was performed in mice bearing tumor xenografts with different levels of CD44 expression and RG7356 responsiveness, namely, MDA-MB231 (CD44+, responsive), PL45 (CD44+, nonresponsive), and HepG2 (CD44-, nonresponsive) [42]. ${ }^{89} \mathrm{Zr}$-RG7356 selectively targeted CD44+ responsive and nonresponsive tumors in mice. ${ }^{89} \mathrm{Zr}$-RG7356 whole body immuno-PET in healthy cynomolgus monkeys revealed antibody uptake in spleen, salivary gland, and bone marrow, which might be related to the expression of CD44 in these organs. The ${ }^{89} \mathrm{Zr}$-RG7356 uptake in the normal organs decreased with increasing dose of unlabeled RG7356, indicating saturable targeting of CD44 in these animals.

5.3. Targeting EGFR. The epidermal growth factor receptor (EGFR) is a member of the ErbB family. It plays a crucial role in differentiation, proliferation, and survival of many different tumor types, including breast, lung bladder, and colon carcinoma [2]. The overexpression of EGFR is associated with more aggressive tumors and poor prognosis due to the resistance of treatment $[43,44]$. Many mAbs have been developed to inhibit the EGFR activation [2]. A well-known example is cetuximab (Erbitux), a chimeric IgG, which upon binding to the ligand-binding domain induces internalization of EGFR and thereby blocking downstream signalling [45, 46]. Several studies showed tumor regression upon treatment with cetuximab [47-50].

${ }^{89} \mathrm{Zr}$-labeled cetuximab was evaluated for scouting the biodistribution of ${ }^{90} \mathrm{Y}$ - and ${ }^{177} \mathrm{Lu}$-cetuximab in tumor bearing mouse and thus potentially allowing the estimation of the radiation dose delivered to tumors and normal tissues during radioimmunotherapy with ${ }^{90} \mathrm{Y}$ - and ${ }^{177} \mathrm{Lu}$-cetuximab [51]. It was reported that the ${ }^{89} \mathrm{Zr}$-immuno-PET could be used for in vivo scouting of ${ }^{90} \mathrm{Y}$ - and ${ }^{177} \mathrm{Lu}$-labeled mAbs. However, an increased bone uptake of ${ }^{89} \mathrm{Zr}$-cetuximab, compared with ${ }^{90} \mathrm{Y}$ - and ${ }^{177} \mathrm{Lu}$ labeled cetuximab, was observed indicating that ${ }^{89} \mathrm{Zr}$ is more efficiently incorporated in the bone compared to the other radiometals $\left({ }^{90} \mathrm{Y}\right.$ - and $\left.{ }^{177} \mathrm{Lu}\right)$. Therefore estimating bone marrow doses based on ${ }^{89} \mathrm{Zr}$-bone uptake is not straightforward. Another study investigated the relation between the in vivo expression of EGFR and the tumor uptake of ${ }^{89} \mathrm{Zr}$-cetuximab [52]. In this study no clear-cut relationship was found, suggesting that apart from antigen 


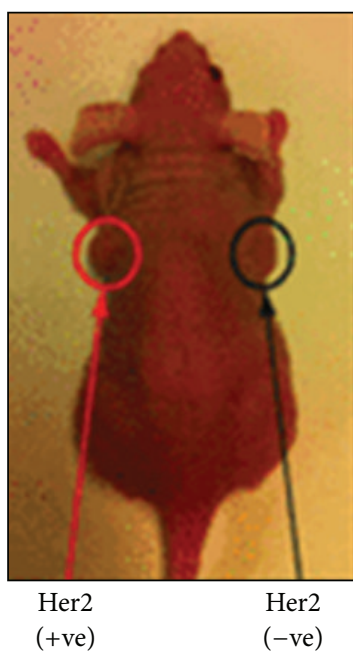

(a)
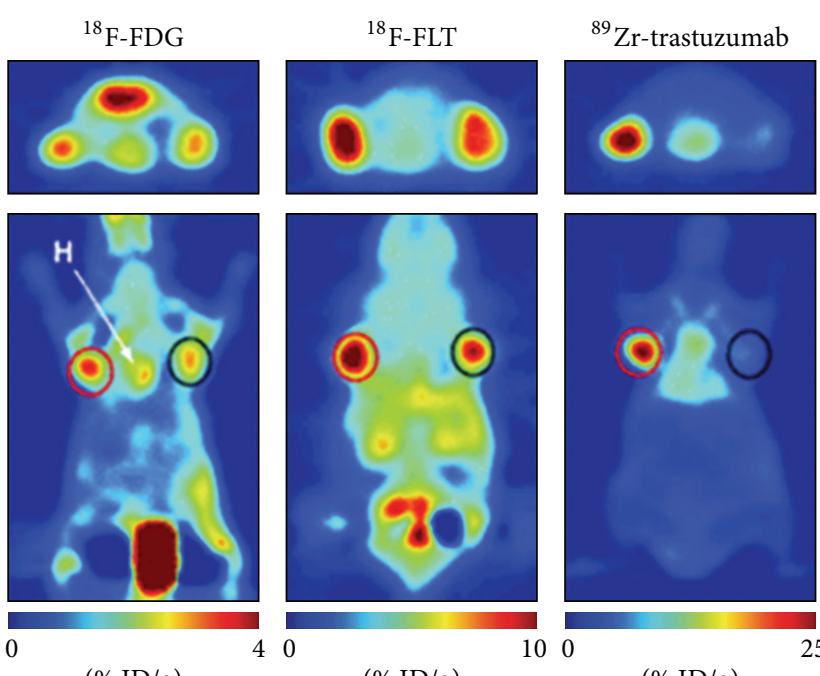

(\% ID/g)

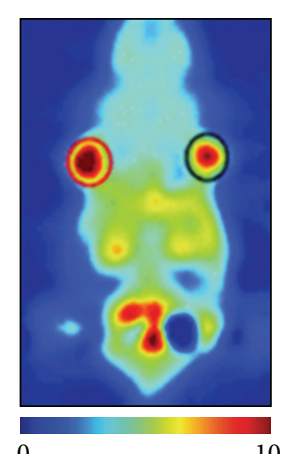

(\% ID/g)

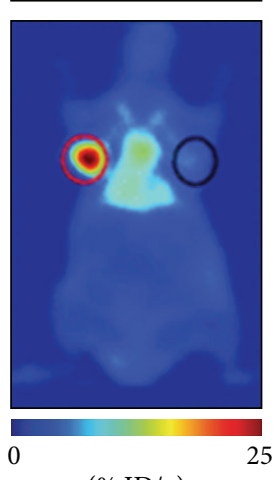

(\% ID/g)

(b)

Figure 2: Specificity of ${ }^{89} \mathrm{Zr}$-trastuzumab for HER2-positive tumors. Coronal ${ }^{89} \mathrm{Zr}$-trastuzumab, ${ }^{18}$ F-FDG, and ${ }^{18}$ F-FLT PET images of athymic nude mice bearing subcutaneous HER2-positive NCI-N87 (left) and HER2-negative MKN-74 (right) are shown. ROIs (\%ID/g) for ${ }^{89} \mathrm{Zr}$-trastuzumab, ${ }^{18} \mathrm{~F}$-FDG, and ${ }^{18} \mathrm{~F}$-FLT are indicated. +ve = positive; -ve = negative. This research was originally published in [3]. $\odot$ by the Society of Nuclear Medicine and Molecular Imaging, Inc.

expression other parameters determine the tumor uptake of ${ }^{89} \mathrm{Zr}$-cetuximab.

Another approved mAb to inhibit the EGFR signalling is panitumumab. It was the first recombinant human monoclonal antibody (IgG2) approved by the FDA for the treatment of patients with EGFR-expressing metastatic colorectal cancer (mCRC) [53]. In several studies the use of panitumumab for noninvasive, in vivo imaging of HER1 expression in tumors is reported [54-58]. The use of ${ }^{89} \mathrm{Zr}$-panitumumab for immuno-PET of HER1 expression was recently evaluated in a direct comparison with ${ }^{111}$ In-panitumumab. The organ biodistribution between ${ }^{111} \mathrm{In}$ - and ${ }^{89} \mathrm{Zr}$-panitumumab was almost identical [55]. In addition, the targeting of ${ }^{89} \mathrm{Zr}$ panitumumab correlated well with the HER1 expression. Recently, a standardized and straightforward stepwise $\sim 5 \mathrm{~h}$ production method was reported for the production of clinical-grade ${ }^{89} \mathrm{Zr}$-panitumumab [59]. In this method clinical-grade panitumumab is conjugated with DFO chelate and subsequently radiolabeled with ${ }^{89} \mathrm{Zr}$ resulting in high yields $(>70 \%)$ and high radiochemical purity $(>98 \%)$.

5.4. Targeting HER2. Human epidermal growth factor receptor 2 (HER2) is another member of the ErbB family. It is involved in angiogenesis, differentiation, metastasis, proliferation, and cell survival upon heterodimerization with other members of the EGF receptor family [60]. HER2 overexpression is found in many types of tumors including breast and ovarian cancer. The FDA approved anti-HER2 mAb trastuzumab (Herceptin, Genentech, CA, USA) to be used for the treatment of HER2 positive breast tumors, since it blocks the HER2 activation [60]. The efficacy of the treatment is dependent on the HER2 expression level. The HER2 expression level in a tumor is not static and may vary over time [60]. In addition, the HER2 expression is found to be different between the primary lesion and the distant metastatic lesions in the same patient. Noninvasive in vivo imaging to visualize HER2 expressing using radiolabeled trastuzumab has been extensively investigated [29, 30, 61]. PET imaging using ${ }^{89} \mathrm{Zr}$-trastuzumab has been performed in different murine tumor models and accumulation of the tracer was found to be HER2 specific $[29,30,61]$. For example, the tumor uptake of ${ }^{89} \mathrm{Zr}$-trastuzumab in nude mice with a subcutaneous human ovarian cancer xenografts (SK-OV-3) was high ( $\sim 30 \% \mathrm{ID} / \mathrm{g}$ ) and the biodistribution was similar to that of ${ }^{111}$ In-trastuzumab [29]. Recently, the specificity of ${ }^{89} \mathrm{Zr}$ trastuzumab, ${ }^{18}$ F-FDG, and ${ }^{18}$ F-FLT PET for HER2-positive gastric cancer was evaluated ([3]; Figure 2). The study revealed a high specific uptake of ${ }^{89} \mathrm{Zr}$-trastuzumab in HER2positive tumors, whereas ${ }^{18}$ F-FDG and ${ }^{18}$ F-FLT PET were unable to differentiate between HER2-positive and HER2negative tumors. In addition, ${ }^{89} \mathrm{Zr}$-trastuzumab was used to quantitatively determine the HER2 expression level after treatment. For example, after treatment with a heat shock protein 90 (hsp90) inhibitor a significant decrease in HER2 expression could be measured based on the ${ }^{89} \mathrm{Zr}$-trastuzumab tumor targeting $[30,62]$. A combination treatment of hsp90 inhibitor 17AAG and the EGFR/HER2 tyrosine kinase inhibitor, lapatinib, revealed an even stronger reduction of the HER2 expression levels using ${ }^{89} \mathrm{Zr}$-Trastuzumab-F $\left(\mathrm{ab}^{\prime}\right)_{2}$ fragment as probe [63]. Additionally, the biological effect of afatinib, an EGFR/HER2/HER4 inhibitor, in a HER2-positive gastric xenograft models was evaluated [3]. In this model the uptake of ${ }^{18}$ F-FDG did not change after afatinib therapy, 
whereas a decrease in ${ }^{89} \mathrm{Zr}$-trastuzumab uptake was observed upon treatment. The lower uptake of the ${ }^{89} \mathrm{Zr}$-trastuzumab correlated with the decreased HER2 expression as determined by immunoblots and immunohistochemistry. Thus, ${ }^{89} \mathrm{Zr}$-trastuzumab PET might be useful for the characterization, treatment planning, and treatment monitoring of HER2 positive cancers.

5.5. Targeting VEGF. Vascular endothelial growth factor (VEGF) is a proangiogenic factor in both normal tissues and in tumors. The overexpression of VEGF and its receptors (VEGFR) are associated with poor prognosis [64]. The humanized anti-VEGF mAb, bevacizumab (Avastin, Genentech/Hoffmann-La Roche), is capable of blocking angiogenesis by depleting VEGF and thereby preventing its binding to the VEGFR. This neutralizes VEGF actions (see, e.g., [65-72]). A direct comparison between ${ }^{89} \mathrm{Zr}$ bevacizumab and an irrelevant ${ }^{89} \mathrm{Zr}$-labeled IgG revealed a significantly higher tumor uptake of ${ }^{89} \mathrm{Zr}$-bevacizumab in nude mice with human ovarian SK-OV-3 tumors [73]. Besides using ${ }^{89} \mathrm{Zr}$-bevacizumab as PET tracer for noninvasive in vivo imaging of VEGF expression in the tumor microenvironment, potentially it can also be used to predict or monitor an antiangiogenic response. For example, hsp90 is crucial player in VEGF transcription and can be used to treat ovarian tumors. In nude mice with a subcutaneous human ovarian cancer xenografts (A2780), uptake of ${ }^{89} \mathrm{Zr}$ bevacizumab in the tumors correlated with the therapeutic effect of the hsp90 inhibitor, NVP-AUY922, [74]. In another study the effect of the mTOR inhibitor, everolimus, on the VEGF production was evaluated [75]. Everolimus treatment caused decreased ${ }^{89} \mathrm{Zr}$-bevacizumab uptake in subcutaneous A2780 human ovarian tumor. The results were in line with the lower VEGF-A protein levels in tumor lysates of treated versus untreated tumors. These results indicate ${ }^{89} \mathrm{Zr}$ bevacizumab can be used to monitor tumor VEGF-A levels as an early biomarker of the antiangiogenic effect of mTOR inhibitor treatment.

${ }^{89} \mathrm{Zr}$-labeled ranibizumab, a monoclonal antibody fragment (Fab) derivative of bevacizumab, was used to detect and monitor the early antiangiogenic response to treatment with sunitinib, a VEGFR tyrosine kinase inhibitor, in nude mice bearing a subcutaneous A2780 human ovarian tumor or Colo205 human colon cancer xenografts. ${ }^{89} \mathrm{Zr}$-ranibizumab PET matched better with the observed results obtained by histology, immunohistochemistry, and tumor proliferation and vascularization assays, than ${ }^{18} \mathrm{~F}$-FDG PET and ${ }^{15} \mathrm{O}$-water PET. Since ranibizumab has a serum half-life of only 2 to 6 hours, rapid and sequential follow-up PET scans are feasible with ${ }^{89} \mathrm{Zr}$-ranibizumab [76]. Therefore, in contrast to ${ }^{89} \mathrm{Zr}$ bevacizumab, ${ }^{89} \mathrm{Zr}$-ranibizumab can be used for imaging of rapid dynamic alterations in VEGF response in tumors.

5.6. Targeting PIGF. The clinical benefits of angiogenesis inhibitors can be compromised by the upregulation of proangiogenic factors such as the placental growth factor (PIGF). PIGF, a VEGF homolog, is expressed in low levels in normal tissue and can be overexpressed in tumor cells. PIGF contributes to angiogenesis in pregnancy, wound healing, ischemic conditions, and tumor growth [77, 78]. PIGF inhibitors are able to reduce the angiogenesis and tumor cell motility. The antitumor activity of a humanized $\mathrm{mAb}$ directed against PIGF-1 and PIGF-2, RO5323441, in human tumor xenograft models has been reported [79]. To further explore and validate the use of RO5323441, the tumor and normal tissue uptake of ${ }^{89} \mathrm{Zr}$-RO5323441 at different time points was evaluated in mice bearing human PlGF-expressing Huh7 hepatocellular cancer xenografts. Tumor accumulation of ${ }^{89} \mathrm{Zr}$-RO5323441 was specific and time- and dose-dependent.

5.7. Targeting PSMA. Prostate-specific membrane antigen (PSMA) is a transmembrane glycoprotein which is associated with increased tumor progression, development of castration resistance, and/or resistance to hormone-based treatments [80-82]. PMSA is expressed in a limited range of normal tissues including benign prostatic epithelium, renal proximal tubule, small bowel, and the brain; however, the expression level is 2 to 3 times lower than in prostate cancer specimens [83]. ${ }^{89} \mathrm{Zr}$-labeled anti-PSMA mAb, J591, was able to differentiate between subcutaneous PSMA positive and negative tumors in athymic nude mice [21], making it a potential target for clinical noninvasive identification and quantification of PSMA-positive tumors.

5.8. Targeting CD147. CD147, a member of the immunoglobulin superfamily, is involved in many physiological functions including embryo implantation, early stage neural network formation, and spermatogenesis [85]. Overexpression of CD147 is found in many types of cancer including pancreatic cancer and induces expression of matrix metalloproteinases (MMPs) and VEGF $[86,87]$. Several (pre-)clinical studies have been performed using anti-CD147 antibodies to inhibit the actions of CD147 and revealed a reduction in proliferation, invasion and metastasis of tumors [88-90]. Almost 90\% of the pancreatic cancers have high CD147 expression levels [86]. Sugyo et al. evaluated the CD147 expression in four pancreatic cancer cell lines (MIA Paca-2, PANC-1, BxPC-3, and AsPC-1) using the human ${ }^{125} \mathrm{I}-,{ }^{67} \mathrm{Ga}-$, or ${ }^{89} \mathrm{Zr}$-labeled anti-CD147 mAb (059-053) [84]. Additionally, the in vivo CD147 expression was evaluated using ${ }^{125} \mathrm{I}$ - or ${ }^{89} \mathrm{Zr}$-labeled 059-053 in mice with s.c. and orthotopic MIA Paca-2 and A4 (non-CD147-expressing) tumors. The biodistribution data revealed significantly higher tumor uptake of ${ }^{89} \mathrm{Zr}-059-053$ in MIA Paca-2 tumors than in the A4 tumors (Figure 3). PET/CT imaging demonstrated that orthotopic MIA Paca-2 tumors could be visualized with ${ }^{89} \mathrm{Zr}$-059-053 PET. High expression of CD147 is not only restricted to pancreatic cancer, but is also found in other types of cancer including bladder, breast, colorectal, cervical, liver, and ovarian cancer [84-86]. Therefore, ${ }^{89} \mathrm{Zr}$-059-053 might also be applied in patients with these cancer types.

5.9. Targeting CAIX. Hypoxia in tumors is associated with a poor prognosis in many tumor types since it is associated with resistance to radiotherapy and chemotherapy. In many tumor types carbonic anhydrase IX (CAIX) has been validated as 


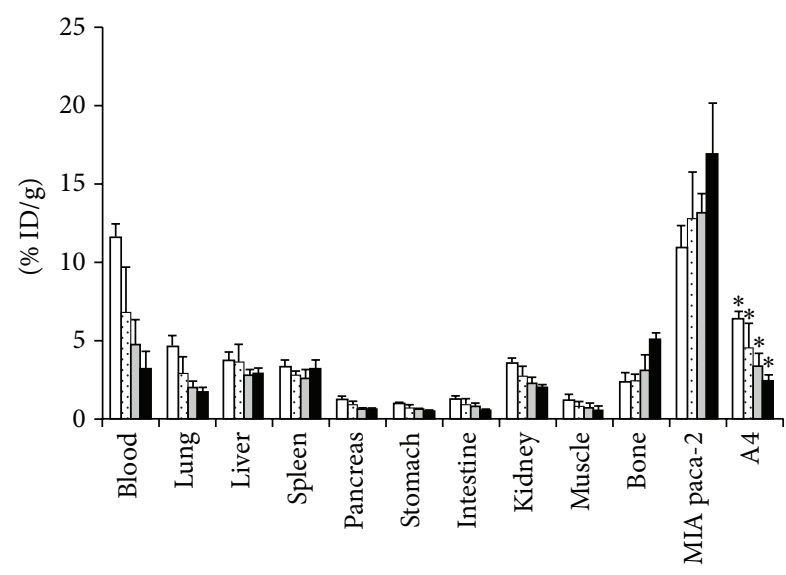

(a)

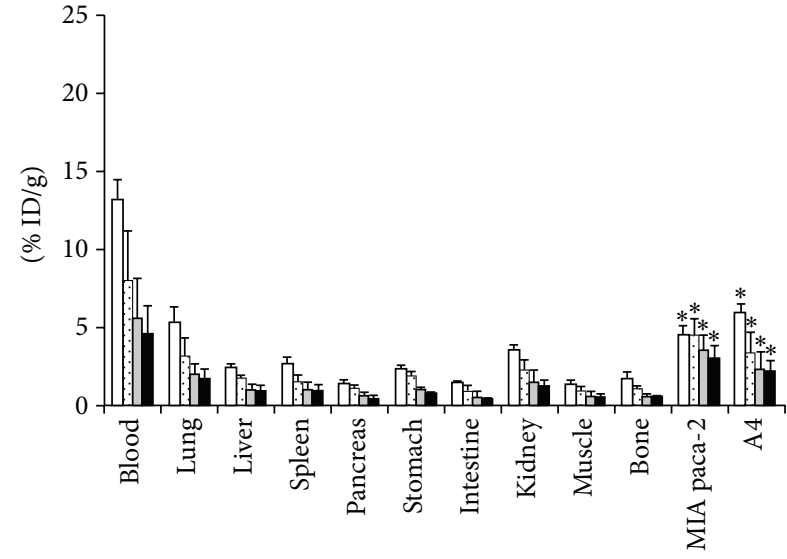

(b)

Figure 3: In vivo biodistribution experiments in nude mice bearing MIA PaCa-2 and A4 xenografts of radiolabeled anti-CD147 antibody 059-053. Samples were collected and weighted, and radioactivity was measured at days 1 (white bars), 2 (dot bars), 4 (gray bars), and 6 (black bars) after intravenous injection of $37 \mathrm{kBq}$ each of ${ }^{89} \mathrm{Zr}-059-053$ (a) and ${ }^{125} \mathrm{I}-059-053$ (b). Data are expressed as mean \pm SD $(n=5)$. ${ }^{*} P<0.01$ versus ${ }^{89} \mathrm{Zr}$-059-053 tumor uptake at each time point analyzed by ANOVA with the Student-Newman-Keuls method multiple comparison test. This research was originally published in [84].

an intrinsic hypoxia-related cell marker [91]. Using antibodies directed against CAIX it is possible to select patients for hypoxia-targeting or -modifying treatment combined with radiotherapy. For example, it is possible to visualize tumor hypoxia in mice bearing s.c. SCCNij3 head and neck squamous cell carcinomas using ${ }^{89} \mathrm{Zr}-\mathrm{cG} 250-\mathrm{F}\left(\mathrm{ab}^{\prime}\right)_{2}$, an antiCAIX antibody fragment [92]. In a direct comparison, the tumor uptake of $\mathrm{mAb}{ }^{89} \mathrm{Zr}-\mathrm{cG} 250$ in mice with CAIXexpressing clear cell renal cell carcinoma (ccRCC) xenografts (NU-12) was significantly higher compared to that of ${ }^{124} \mathrm{I}-$ cG250 [93]. This indicates that PET imaging of ccRCC tumors with ${ }^{89} \mathrm{Zr}$-cG250 could be more sensitive than ${ }^{124} \mathrm{I}-\mathrm{cG} 250$ PET. CAIX targeted ${ }^{89} \mathrm{Zr}$-PET imaging is a candidate for imaging hypoxia in different types of tumors and deserves further exploration.

5.10. Targeting $I G F-1 R$. The insulin like growth factor 1 receptor (IGF-1R) is a transmembrane receptor expressed in many human cancers, including in $\sim 35 \%$ of all triple-negative breast carcinomas. It is involved in the proliferation, apoptosis, angiogenesis, and tumor invasion. Heskamp et al. reported excellent tracer uptake of ${ }^{111} \mathrm{In}-\mathrm{R} 1507$ and ${ }^{89} \mathrm{Zr}$ R1507, a human mAb directed against IGF-1R, in mice with s.c. SUM149 triple-negative breast cancer xenografts [94]. This suggests that the use of ${ }^{89} \mathrm{Zr}$-R1507 in patient selection of IGF-1R-targeted therapy is possible.

5.11. Targeting Met. The expression of hepatocyte growth factor receptor tyrosine kinase (Met) was measured by PET using ${ }^{76} \mathrm{Br}$ or ${ }^{89} \mathrm{Zr}$-labeled-onartuzumab, a mAb against Met [95]. Both tracers specifically targeted Met; however, at later time points a higher tumor uptake was observed with ${ }^{89} \mathrm{Zr}$ Onartuzumab. This suggests that ${ }^{89} \mathrm{Zr}$-onartuzumab is the preferred tracer to identify Met expression in cancer patients and possibly to predict and monitor the treatment with
Met-targeted therapeutics. In another study, the potential of immune-PET using ${ }^{89} \mathrm{Zr}$ (residualising radionuclide) or ${ }^{124}$ I-labeled (non-residualising radionuclide) anti-Met $\mathrm{mAb}$ DN30 was evaluated in mice with s.c. GLT-16 (high Met expression) and $\mathrm{FaDu}$ (low Met expression) tumors [96]. The biodistribution data revealed significantly higher tumor uptake of ${ }^{89} \mathrm{Zr}$-DN30 than ${ }^{124}$ I-DN30 in GTL-16 tumorbearing mice. Similar blood levels were found indicating that DN30 is internalized. ${ }^{89} \mathrm{Zr}$-DN30 immuno-PET imaging was able to visualize small tumor lesions with a higher ${ }^{89} \mathrm{Zr}$ tumor uptake in GTL-16 than FaDu tumor-bearing mice. Additionally, the correlation was high for PET-image-derived ${ }^{89} \mathrm{Zr}$ tumor uptake and the ex vivo-assessed ${ }^{89} \mathrm{Zr}$ tumor uptake. This indicates that ${ }^{89} \mathrm{Zr}$-labeled immuno-PET is an attractive method to evaluate Met-targeted therapeutics.

5.12. Targeting GPC3. The glypican-3 (GPC3) is a hepatocellular-specific cell surface proteoglycan overexpressed in most hepatocellular carcinomas (HCC). Sham et al. reported excellent tracer uptake of ${ }^{89} \mathrm{Zr}-\alpha \mathrm{GPC} 3$, a mAb directed against GPC3, in mice with GPC3-expressing HepG2 liver tumors [97]. This suggests that the use of ${ }^{89} \mathrm{Zr}-\alpha \mathrm{GPC} 3$ to image HCC in the liver is possible.

\section{Clinical Translation of ${ }^{89} \mathrm{Zr}$ Immuno-PET}

The ${ }^{89} \mathrm{Zr}$-labeled antibodies against the targets mentioned above all show promising results for clinical translation. To date, several clinical investigations using ${ }^{89} \mathrm{Zr}$-labeled antibody constructs have been reported $[1,22,98]$. Here these recent clinical studies will be discussed.

6.1. ${ }^{89} \mathrm{Zr}$-Labeled $c U 36$. The first clinical trial using the ${ }^{89} \mathrm{Zr}$ cU36 PET to target CD44 expressing tumors showed that 
the tracer was able to detect primary tumors as well as metastases in the neck region with similar sensitivity as computed tomography (CT) and magnetic resonance imaging (MRI) [99]. The results are promising, although several issues remain to be addressed. In the clinical study micrometastases were missed with ${ }^{89} \mathrm{Zr}$-cU36 PET, so immuno-PET may be less suited as a staging tool, but more suitable to characterize tumors. Moreover, 2 out of the 20 patients developed antibodies against the chimeric cU36 antibody (HACA), which may hinder repetitive imaging procedures.

6.2. ${ }^{89} \mathrm{Zr}$-Ibritumomab. A clinical prospective study was conducted to evaluate the biodistribution and radiation dosimetry of CD20-targeting ${ }^{90}$ Y-ibritumomab tiuxetan using ${ }^{89} \mathrm{Zr}$ ibritumomab tiuxetan [100]. Patients with relapsed or refractory aggressive B-cell (CD20-positive) NHL underwent a PET scan at 1,72 and $144 \mathrm{~h}$ after injection of $70 \mathrm{MBq}{ }^{89} \mathrm{Zr}$ ibritumomab tiuxetan and again 2 weeks later after coinjection of $15 \mathrm{MBq} / \mathrm{kg}$ or $30 \mathrm{MBq} / \mathrm{kg}{ }^{90} \mathrm{Y}$-ibritumomab tiuxetan. The results revealed that simultaneous therapy of ${ }^{90} \mathrm{Y}$ ibritumomab tiuxetan did not affect the biodistribution of ${ }^{89} \mathrm{Zr}$-ibritumomab. A second aim of the study was to estimate the radiation doses during radioimmunotherapy with ${ }^{90} \mathrm{Y}$ ibritumomab tiuxetan based on ${ }^{89} \mathrm{Zr}$-ibritumomab PET. The highest ${ }^{90} \mathrm{Y}$ absorbed dose was observed in liver $(3.2 \pm$ $1.8 \mathrm{mGy} / \mathrm{MBq})$ followed by the spleen $(2.9 \pm 0.7 \mathrm{mGy} / \mathrm{MBq})$. Additionally, the correlation was high for standardized uptake value (SUV) of ${ }^{89} \mathrm{Zr}$-ibritumomab tiuxetan and absorbed dose of ${ }^{90}$ Y-ibritumomab tiuxetan in the liver at $72 \mathrm{~h}$ p.i. and $144 \mathrm{~h}$ p.i. This suggests that in the future a single ${ }^{89} \mathrm{Zr}$ ibritumomab tiuxetan PET scan is sufficient to optimize the administered amount of ${ }^{90} \mathrm{Y}$-ibritumomab tiuxetan RIT for individual patients

6.3. ${ }^{89} \mathrm{Zr}$-Trastuzumab. In 2010 , the first-in-man report of ${ }^{89} \mathrm{Zr}$-trastuzumab for imaging of HER2-positive lesions in patients with metastatic breast cancer was published [101]. 14 Patients were included in the study that either received 10 $(n=2)$ or $50(n=5) \mathrm{mg}^{89} \mathrm{Zr}$-trastuzumab if trastuzumabnaïve and $10 \mathrm{mg}{ }^{89} \mathrm{Zr}$-trastuzumab $(n=7)$ if on trastuzumab treatment $\left(37 \mathrm{MBq}{ }^{89} \mathrm{Zr}\right.$-trastuzumab). Per patient at least two PET scans were acquired between day 2 and day 5 after injection of ${ }^{89} \mathrm{Zr}$-trastuzumab. The trastuzumab-naïve patients required a $50 \mathrm{mg}$ dose for effective imaging whereas $10 \mathrm{mg}$ was sufficient in the trastuzumab-treated patients. A higher dose in the trastuzumab-naive patients was required as an increased ${ }^{89} \mathrm{Zr}$-trastuzumab clearance was observed at lower doses due to presence of extracellular domains of the HER2 receptor in the circulation [102]. After binding of ${ }^{89} \mathrm{Zr}$-trastuzumab to these extracellular domains, the immune complex was cleared by the liver and excreted in the intestines. In patients treated with trastuzumab at the time of injection, higher doses of ${ }^{89} \mathrm{Zr}$-trastuzumab did not improve imaging since complex formation was minimal. Overall, the uptake of ${ }^{89} \mathrm{Zr}$-trastuzumab in the tumor lesions was high. The best time to assess tumor uptake was 4 to 5 days after injection of ${ }^{89} \mathrm{Zr}$-trastuzumab (Figure 4). All the known and even some unknown lesions were detected with PET. Of interest, metastatic brain lesions were detected in several patients, despite the fact that trastuzumab cannot penetrate the blood-brain barrier. This is probably because the blood-brain barrier in patients with brain metastasis is disrupted allowing ${ }^{89} \mathrm{Zr}$-trastuzumab to pass. In this study HER2 overexpressing lesions could be distinguished from non-HER2 expressing lesions. These data indicate the potential use of ${ }^{89} \mathrm{Zr}$-trastuzumab to improve the diagnosis of patients with HER2-positive breast cancer especially when lesions are inaccessible for biopsy.

6.4. ${ }^{89} \mathrm{Zr}$-Bevacizumab. Recently, a clinical study was performed to assess the use of ${ }^{89} \mathrm{Zr}$-bevacizumab for the visualization of VEGF-A in primary breast cancer [103]. In 23 patients, 26 tumors were detected by conventional imaging modalities mammography $(n=22)$, ultrasound $(n=25)$, or MRI $(n=1)$. Prior to surgery and 4 days p.i. of $37 \mathrm{MBq}$ of ${ }^{89} \mathrm{Zr}$-bevacizumab the patients underwent a PET/CT scan of the breasts and the axillary regions (Figure 5(a)). 25 of the 26 breast cancer nodules (96.1\%) were detected using ${ }^{89} \mathrm{Zr}$ bevacizumab. Also, a correlation between the VEGF-A protein level in the tumors observed as measured by VEGFA ELISA and the tumor uptake ${ }^{89} \mathrm{Zr}$-bevacizumab was found (Figure 5(b)). This study provides evidence that ${ }^{89} \mathrm{Zr}$ bevacizumab might be a potential candidate for the classification of breast tumors and to predict and monitor the effect of VEGF-A targeted therapies.

\section{Conclusions}

Clinical studies revealed that the use of ${ }^{89} \mathrm{Zr}$-based immunoPET results in high spatial resolution images with high tumor uptake and a good signal to noise ratio. Therefore, the use of ${ }^{89} \mathrm{Zr}$-labeled antibodies is very promising for noninvasive visualization of tumor-associated antigens before, during, and after therapy. This makes ${ }^{89} \mathrm{Zr}$-based immuno-PET an excellent imaging modality to predict and monitor treatment and to tailor treatment for individual patients. However, to fully integrate ${ }^{89} \mathrm{Zr}$-based immuno-PET in the clinic several hurdles still need to be overcome. For example, standardized and robust methods for stable conjugation of DFO to antibodies should become available to obtain clinical-grade conjugates. In addition, research should focus on the development of improved chelators to minimize the amount of liberated $\mathrm{Zr}^{4+}$. Although some direct comparison studies between ${ }^{89} \mathrm{Zr}$-based immuno-PET and immuno-PET using other PET isotopes have been performed, and supplementary quantitative and comprehensive comparison studies are needed to evaluate the value of ${ }^{89} \mathrm{Zr}$-based immuno-PET. Additionally, the radiation dose for patients undergoing a ${ }^{89} \mathrm{Zr}$-based immuno-PET (75 MBq of ${ }^{89} \mathrm{Zr}$-cmAb U36) was found to result in a mean effective dose of 0.53 to $0.66 \mathrm{mSv} / \mathrm{MBq}$ [104] which is significantly higher compared to the mean effective dose of clinically used ${ }^{111} \mathrm{In}$ - and ${ }^{99} \mathrm{Tcm}$ based tracers $\left({ }^{111} \mathrm{In}-\mathrm{IgG}(75 \mathrm{MBq})\right.$ was $0.25 \mathrm{mSv} / \mathrm{MBq}$ and ${ }^{99} \mathrm{Tcm}-\mathrm{IgG}$ (750 MBq) was mu Sv/MBq) [105]. The high 


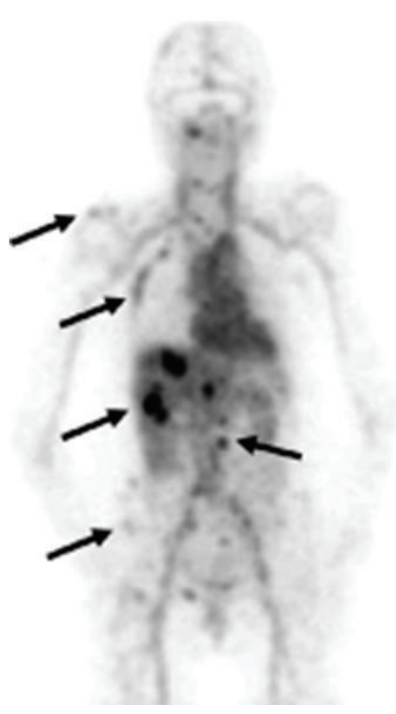

(a)

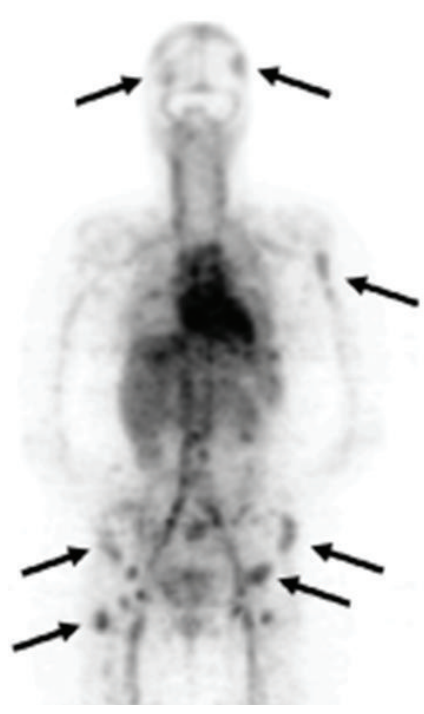

(b)

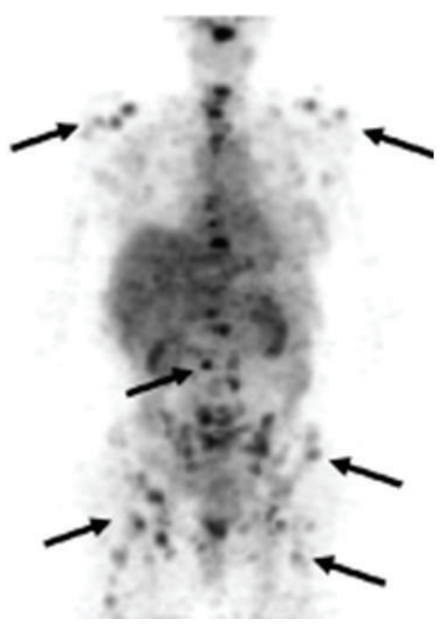

(c)

FIGURE 4: Examples of ${ }^{89}$ Zr-trastuzumab uptake 5 days after the injection: (a) a patient with liver and bone metastases and ((b) and (c)) two patients with multiple bone metastases. A number of lesions have been specifically indicated by arrows. This research was originally published in [101].
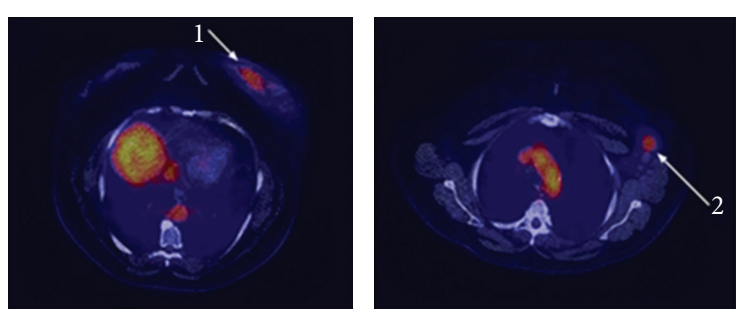

(a)

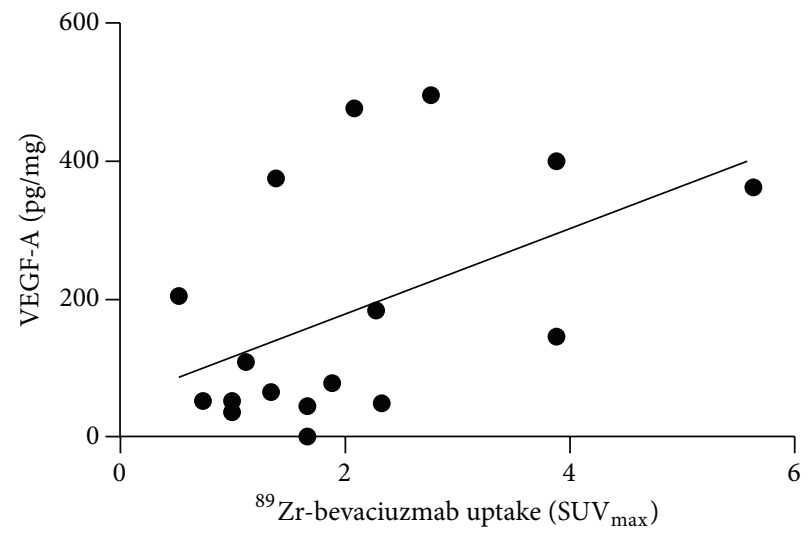

(b)

FIGURE 5: (a) Axial slices of ${ }^{89} \mathrm{Zr}$-bevacizumab PET from patient with primary breast tumor (1) and lymph node metastasis (2). (b) Correlation between ${ }^{89} \mathrm{Zr}$-bevacizumab tumor uptake ( $x$-axis) and tumor VEGF-A ( $y$-axis) levels as measured by ELISA (Pearson $\left.r=0.49, P=0.04\right)$. This research was originally published in [103]. () by the Society of Nuclear Medicine and Molecular Imaging, Inc.

radiation dose for patients will limit repeated application of ${ }^{89} \mathrm{Zr}$-based immuno-PET [104]. However, introducing new PET/CT scanners to allow better-quality immuno-PET images to be obtained with a lower ${ }^{89} \mathrm{Zr}$ radioactivity $(37 \mathrm{MBq})$ dose have reduced the radiation dose $[102,103]$. Furthermore, research is focusing on combining ${ }^{89} \mathrm{Zr}$-based immuno-PET with other imaging modalities. For example, the use of ${ }^{89} \mathrm{Zr}$-immuno-PET in combination with nearinfrared fluorescence (NIRF) imaging has been reported by several groups [106-108]. The ongoing development of new ${ }^{89} \mathrm{Zr}$-labeled antibodies directed against novel tumor targets is believed to rapidly expand applications of ${ }^{89} \mathrm{Zr}$-labeled immuno-PET to a valuable method in the medical imaging.

\section{Conflict of Interests}

The authors declare that there is no conflict of interests regarding the publication of this paper.

\section{References}

[1] Y. Zhang, H. Hong, and W. Cai, "PET tracers based on zirconium-89," Current Radiopharmaceuticals, vol. 4, no. 2, pp. 131139, 2011.

[2] R. S. Herbst and D. M. Shin, "Monoclonal antibodies to target epidermal growth factor receptor-positive tumors: a new paradigm for cancer therapy," Cancer, vol. 94, no. 5, pp. $1593-$ 1611, 2002. 
[3] Y. Y. Janjigian, N. Viola-Villegas, J. P. Holland et al., "Monitoring afatinib treatment in HER2-positive gastric cancer with $18 \mathrm{~F}$ FDG and ${ }^{89} \mathrm{Zr}$-trastuzumab PET,' Journal of Nuclear Medicine, vol. 54, no. 6, pp. 936-943, 2013.

[4] C. H. Muselaers, A. B. Stillebroer, I. M. Desar et al., "Tyrosine kinase inhibitor sorafenib decreases ${ }^{111}$ In-girentuximab uptake in patients with clear cell renal cell carcinoma," Journal of Nuclear Medicine, vol. 55, no. 2, pp. 242-247, 2014.

[5] T. J. Wadas, E. H. Wong, G. R. Weisman, and C. J. Anderson, "Coordinating radiometals of copper, gallium, indium, yttrium, and zirconium for PET and SPECT imaging of disease," Chemical Reviews, vol. 110, no. 5, pp. 2858-2902, 2010.

[6] M. Lubberink and H. Herzog, "Quantitative imaging of ${ }^{124} \mathrm{I}$ and ${ }^{86} \mathrm{Y}$ with PET," European Journal of Nuclear Medicine and Molecular Imaging, vol. 38, supplement 1, pp. S10-S18, 2011.

[7] J. M. Link, K. A. Krohn, J. F. Eary et al., "Sixth international symposium on radiopharmaceutical chemistry. Abstracts. Part III," Journal of Labelled Compounds and Radiopharmaceuticals, vol. 23, no. 10-12, p. 1297, 1986.

[8] A. Kasbollah, P. Eu, S. Cowell, and P. Deb, "Review on production of ${ }^{89} \mathrm{Zr}$ in a medical cyclotron for PET radiopharmaceuticals," Journal of Nuclear Medicine Technology, vol. 41, no. 1, pp. 35-41, 2013.

[9] I. Verel, G. W. Visser, R. Boellaard, M. Stigter-van Walsum, G. B. Snow, and G. A. van Dongen, " ${ }^{89} \mathrm{Zr}$ immuno-PET: comprehensive procedures for the production of ${ }^{89} \mathrm{Zr}$-labeled monoclonal antibodies," Journal of Nuclear Medicine, vol. 44, no. 8, pp. 12711281, 2003.

[10] W. E. Meijs, J. D. M. Herscheid, H. J. Haisma et al., "Production of highly pure no-carrier added ${ }^{89} \mathrm{Zr}$ for the labelling of antibodies with a positron emitter," Applied Radiation and Isotopes, vol. 45, no. 12, pp. 1143-1147, 1994.

[11] J. P. Holland, Y. Sheh, and J. S. Lewis, "Standardized methods for the production of high specific-activity zirconium-89," Nuclear Medicine and Biology, vol. 36, no. 7, pp. 729-739, 2009.

[12] A. L. Wooten, G. D. Schweitzer, L. A. Lawrence, E. Madrid, and S. E. Lapi, "An automated system for production of ${ }^{89} \mathrm{Zr}$," in Proceedings of the 14th International Workshop on Targetry and Target Chemistry (WTTC '12), vol. 1509 of AIP Conference, pp. 201-205, Playa del Carmen, México, August 2012.

[13] J. Siikanen, M. Peterson, T. A. Tran, P. Roos, T. Ohlsson, and A. Sandell, "A peristaltic pump driven ${ }^{89} \mathrm{Zr}$ separation module," in Proceedings of the 14th International Workshop on Targetry and Target Chemistry (WTTC '12), vol. 1509 of AIP Conference, pp. 206-210, Playa del Carmen, México, August 2012.

[14] A. L. Wooten, E. Madrid, and G. D. Schweitzer, "Routine production of ${ }^{89} \mathrm{Zr}$ using an automated module," Applied Sciences, vol. 3, no. 3, pp. 593-613, 2013.

[15] J. D. M. Herscheid, C. M. Vos, and A. Hoekstra, "Manganese$52 \mathrm{~m}$ for direct application: a new $52 \mathrm{Fe} / 52 \mathrm{mMn}$ generator based on a hydroxamate resin," The International Journal of Applied Radiation and Isotopes, vol. 34, no. 6, pp. 883-886, 1983.

[16] D. S. Abou, T. Ku, and P. M. Smith-Jones, "In vivo biodistribution and accumulation of ${ }^{89} \mathrm{Zr}$ in mice," Nuclear Medicine and Biology, vol. 38, no. 5, pp. 675-681, 2011.

[17] W. M. Al Lawati, J. S. Jean, T. R. Kulp et al., "Characterisation of organic matter associated with groundwater arsenic in reducing aquifers of Southwestern Taiwan," Journal of Hazardous Materials, vol. 262, pp. 970-979, 2013.

[18] L. R. Perk, O. J. Visser, M. Stigter-van Walsum et al., "Preparation and evaluation of ${ }^{89} \mathrm{Zr}$-Zevalin for monitoring of ${ }^{90} \mathrm{Y}$ Zevalin biodistribution with positron emission tomography,"
European Journal of Nuclear Medicine and Molecular Imaging, vol. 33, no. 11, pp. 1337-1345, 2006.

[19] T. Kiss and E. Farkas, "Metal-binding ability of desferrioxamine B," Journal of Inclusion Phenomena and Molecular Recognition in Chemistry, vol. 32, no. 2-3, pp. 385-403, 1998.

[20] W. E. Meijs, J. D. Herscheid, H. J. Haisma, and H. M. Pinedo, "Evaluation of desferal as a bifunctional chelating agent for labeling antibodies with Zr-89," International Journal of Radiation Applications and Instrumentation A: Applied Radiation and Isotopes, vol. 43, no. 12, pp. 1443-1447, 1992.

[21] J. P. Holland, V. Divilov, N. H. Bander, P. M. Smith-Jones, S. M. Larson, and J. S. Lewis, "899 Zr-DFO-J591 for immunoPET of prostate-specific membrane antigen expression in vivo," Journal of Nuclear Medicine, vol. 51, no. 8, pp. 1293-1300, 2010.

[22] M. A. Deri, B. M. Zeglis, L. C. Francesconi, and J. S. Lewis, "PET imaging with ${ }^{89} \mathrm{Zr}$ : from radiochemistry to the clinic," Nuclear Medicine and Biology, vol. 40, no. 1, pp. 3-14, 2013.

[23] L. Perk, M. W. D. Vosjan, G. W. Visser et al., "p-isothiocyanatobenzyl-desferrioxamine: a new bifunctional chelate for facile radiolabeling of monoclonal antibodies with zirconium89 for immuno-PET imaging," European Journal of Nuclear Medicine and Molecular Imaging, vol. 37, no. 2, pp. 250-259, 2010.

[24] F. Guerard, Y.-S. Lee, R. Tripier, L. P. Szajek, J. R. Deschamps, and M. W. Brechbiel, "Investigation of $\mathrm{Zr}(\mathrm{IV})$ and ${ }^{89} \mathrm{Zr}(\mathrm{IV})$ complexation with hydroxamates: progress towards designing a better chelator than desferrioxamine B for immuno-PET imaging," Chemical Communications, vol. 49, no. 10, pp. 1002-1004, 2013.

[25] S. Bhattacharyya, K. Kurdziel, L. Wei et al., "Zirconium-89 labeled panitumumab: a potential immuno-PET probe for HER1-expressing carcinomas," Nuclear Medicine and Biology, vol. 40, no. 4, pp. 451-457, 2013.

[26] D. J. Vugts, G. W. Visser, and G. A. van Dongen, " ${ }^{89}$ Zr-PET radiochemistry in the development and application of therapeutic monoclonal antibodies and other biologicals," Current Topics in Medicinal Chemistry, vol. 13, no. 4, pp. 446-457, 2013.

[27] K. Leung, " ${ }^{89}$ Zr-desferrioxamine b-j591 anti-prostate-specific membrane antigen monoclonal antibody," in Molecular Imaging and Contrast Agent Database (MICAD), National Center for Biotechnology Information, Bethesda, Md, USA, 2004.

[28] A. Chopra, " 89 Zr-labeled p-isothiocyanatobenzyl-desferrioxamine b (df-bz-ncs)-conjugated panitumumab, a fully human monoclonal antibody directed against the extracellular domain III of the epidermal growth factor receptor," in Molecular Imaging and Contrast Agent Database (MICAD), National Center for Biotechnology Information, Bethesda, Md, USA, 2004.

[29] E. C. Dijkers, J. G. Kosterink, A. P. Rademaker et al., "Development and characterization of clinical-grade ${ }^{89} \mathrm{Zr}$ - trastuzumab for HER2/neu immunoPET imaging," Journal of Nuclear Medicine, vol. 50, no. 6, pp. 974-981, 2009.

[30] T. H. Oude Munnink, M. A. de Korte, W. B. Nagengast et al., "89 Zr-trastuzumab PET visualises HER2 downregulation by the HSP90 inhibitor NVP-AUY922 in a human tumour xenograft," European Journal of Cancer, vol. 46, no. 3, pp. 678-684, 2010.

[31] J. N. Tinianow, H. S. Gill, A. Ogasawara et al., "Site-specifically ${ }^{89}$ Zr-labeled monoclonal antibodies for ImmunoPET," Nuclear Medicine and Biology, vol. 37, no. 3, pp. 289-297, 2010.

[32] B. M. Zeglis, P. Mohindra, G. I. Weissmann et al., "Modular strategy for the construction of radiometalated antibodies for positron emission tomography based on inverse electron 
demand diels-alder click chemistry," Bioconjugate Chemistry, vol. 22, no. 10, pp. 2048-2059, 2011.

[33] D. J. Vugts, A. Vervoort, M. Stigter-van Walsum et al., "Synthesis of phosphine and antibody-azide probes for in vivo staudinger ligation in a pretargeted imaging and therapy approach," Bioconjugate Chemistry, vol. 22, no. 10, pp. 2072-2081, 2011.

[34] B. M. Zeglis, C. B. Davis, R. Aggeler et al., "Enzyme-mediated methodology for the site-specific radiolabeling of antibodies based on catalyst-free click chemistry," Bioconjugate Chemistry, vol. 24, no. 6, pp. 1057-1067, 2013.

[35] G. Fischer, U. Seibold, R. Schirrmacher, B. Wängler, and C. Wängler, " ${ }^{899} \mathrm{Zr}$, a radiometal nuclide with high potential for molecular imaging with pet: chemistry, applications and remaining challenges," Molecules, vol. 18, no. 6, pp. 6469-6490, 2013.

[36] H. H. Yeh, K. Ogawa, J. Balatoni et al., "Molecular imaging of active mutant L858R EGF receptor (EGFR) kinase-expressing nonsmall cell lung carcinomas using PET/CT,' Proceedings of the National Academy of Sciences of the United States of America, vol. 108, no. 4, pp. 1603-1608, 2011.

[37] A. Natarajan, F. Habte, and S. S. Gambhir, "Development of a novel long-lived immunoPET tracer for monitoring lymphoma therapy in a humanized transgenic mouse model," Bioconjugate Chemistry, vol. 23, no. 6, pp. 1221-1229, 2012.

[38] D. S. Webb, Y. Shimizu, G. A. van Seventer, S. Shaw, and T. L. Gerrard, "LFA-3, CD44, and CD45: physiologic triggers of human monocyte TNF and IL-1 release," Science, vol. 249, no. 4974, pp. 1295-1297, 1990.

[39] J. W. Mulder, P. M. Kruyt, M. Sewnath et al., "Colorectal cancer prognosis and expression of exon-v6-containing CD44 proteins," The Lancet, vol. 344, no. 8935, pp. 1470-1472, 1994.

[40] I. Verel, G. W. Visser, R. Boellaard et al., "Quantitative ${ }^{89} \mathrm{Zr}$ immuno-PET for in vivo scouting of 90Y-labeled monoclonal antibodies in xenograft-bearing nude mice," Journal of Nuclear Medicine, vol. 44, no. 10, pp. 1663-1670, 2003.

[41] I. Verel, G. W. Visser, O. C. Boerman et al., "Long-lived positron emitters zirconium-89 and iodine-124 for scouting of therapeutic radioimmunoconjugates with PET," Cancer Biotherapy and Radiopharmaceuticals, vol. 18, no. 4, pp. 655-661, 2003.

[42] D. Vugts, D. Heuveling, M. Stigter-van Walsum et al., "Preclinical evaluation of ${ }^{89} \mathrm{Zr}$-labeled anti-CD44 monoclonal antibody RG7356 in mice and cynomolgus monkeys: prelude to phase 1 clinical studies," MAbs, vol. 6, no. 2, pp. 567-575, 2013.

[43] F. Meric-Bernstam and M.-C. Hung, "Advances in targeting human epidermal growth factor receptor-2 signaling for cancer therapy," Clinical Cancer Research, vol. 12, no. 21, pp. 6326-6330, 2006.

[44] H. J. Burstein, "The distinctive nature of HER2-positive breast cancers," The New England Journal of Medicine, vol. 353, no. 16, pp. 1652-1654, 2005.

[45] B. A. W. Hoeben, J. D. M. Molkenboer-Kuenen, W. J. G. Oyen et al., "Radiolabeled cetuximab: dose optimization for epidermal growth factor receptor imaging in a head-and-neck squamous cell carcinoma model," International Journal of Cancer, vol. 129, no. 4, pp. 870-878, 2011.

[46] L. Koi, R. Bergmann, K. Brüchner et al., "Radiolabeled antiEGFR-antibody improves local tumor control after external beam radiotherapy and offers theragnostic potential," Radiotherapy and Oncology, vol. 110, no. 2, pp. 362-369, 2014.

[47] P. Specenier and J. B. Vermorken, "Cetuximab: its unique place in head and neck cancer treatment," Biologics, vol. 7, no. 1, pp. 77-90, 2013.
[48] C. Jones, M. A. Taylor, and B. McWilliams, "The role of cetuximab as first-line treatment of colorectal liver metastases," $H P B$, vol. 15, no. 1, pp. 11-17, 2013.

[49] K. Boyd, S. M. Shea, and J. Patterson, "Cetuximab for treatment of advanced squamous cell carcinoma in solid organ transplant recipients," Wiener Medizinische Wochenschrift, vol. 163, no. 1516, pp. 372-375, 2013.

[50] K. Unger, U. Niehammer, A. Hahn et al., "Treatment of metastatic colorectal cancer with cetuximab: influence on the quality of life," Zeitschrift für Gastroenterologie, vol. 51, no. 8, pp. 733-739, 2013.

[51] L. R. Perk, G. W. Visser, M. J. Vosjan et al., " ${ }^{\text {89 }} \mathrm{Zr}$ as a PET surrogate radioisotope for scouting biodistribution of the therapeutic radiometals ${ }^{90} \mathrm{Y}$ and ${ }^{177} \mathrm{Lu}$ in tumor-bearing nude mice after coupling to the internalizing antibody cetuximab," Journal of Nuclear Medicine, vol. 46, no. 11, pp. 1898-1906, 2005.

[52] H. J. Aerts, L. Dubois, L. Perk et al., "Disparity between in vivo EGFR expression and ${ }^{89} \mathrm{Zr}$-labeled cetuximab uptake assessed with PET," Journal of Nuclear Medicine, vol. 50, no. 1, pp. 123131, 2009.

[53] M. Wu, A. Rivkin, and T. Pham, "Panitumumab: human monoclonal antibody against epidermal growth factor receptors for the treatment of metastatic colorectal cancer," Clinical Therapeutics, vol. 30, no. 1, pp. 14-30, 2008.

[54] K. E. Day, L. Sweeny, B. Kulbersh, K. R. Zinn, and E. L. Rosenthal, "Preclinical comparison of near-infrared-labeled cetuximab and panitumumab for optical imaging of head and neck squamous cell carcinoma," Molecular Imaging and Biology, vol. 15, no. 6, pp. 722-729, 2013.

[55] A. J. Chang, R. A. de Silva, and S. E. Lapi, "Development and characterization of ${ }^{89} \mathrm{Zr}$-labeled panitumumab for immunopositron emission tomographic imaging of the epidermal growth factor receptor," Molecular Imaging, vol. 12, no. 1, pp. 1727, 2013.

[56] L. Shan, "Activatable alexa fluor680-conjugated panitumumab and indocyanine green-conjugated trastuzumab cocktail," in Molecular Imaging and Contrast Agent Database (MICAD), National Center for Biotechnology Information, Bethesda, Md, USA, 2004

[57] A. Chopra, “111 In-labeled panitumumab, a fully human monoclonal antibody directed against the extracellular domain III of the epidermal growth factor receptor," in Molecular Imaging and Contrast Agent Database (MICAD), National Center for Biotechnology Information, Bethesda, Md, USA, 2004.

[58] K. J. Wong, K. E. Baidoo, T. K. Nayak, K. Garmestani, M. W. Brechbiel, and D. E. Milenic, "In vitro and in vivo pre-clinical analysis of a $\mathrm{F}\left(\mathrm{ab}^{\prime}\right)_{2}$ fragment of panitumumab for molecular imaging and therapy of HER1-positive cancers," EJNMMI Research, vol. 1, no. 1, pp. 1-15, 2011.

[59] L. Wei, J. Shi, G. Afari, and S. Bhattacharyya, "Preparation of clinical-grade ${ }^{89} \mathrm{Zr}$-panitumumab as a positron emission tomography biomarker for evaluating epidermal growth factor receptor-targeted therapy," Journal of Labelled Compounds and Radiopharmaceuticals, vol. 57, no. 1, pp. 25-35, 2014.

[60] M. E. Gross, R. L. Shazer, and D. B. Agus, "Targeting the HERkinase axis in cancer," Seminars in Oncology, vol. 31, supplement 3, no. 1, pp. 9-20, 2004.

[61] A. J. Chang, R. DeSilva, S. Jain, K. Lears, B. Rogers, and S. Lapi, "89 Zr-radiolabeled trastuzumab imaging in orthotopic and metastatic breast tumors," Pharmaceuticals, vol. 5, no. 1, pp. 7993, 2012. 
[62] J. P. Holland, E. Caldas-Lopes, V. Divilov et al., "Measuring the pharmacodynamic effects of a novel Hsp90 inhibitor on HER2/neu expression in mice using ${ }^{89} \mathrm{Zr}$-DFO-trastuzumab," PLoS ONE, vol. 5, no. 1, Article ID e8859, 2010.

[63] T. H. Oude Munnink, E. G. de Vries, S. R. Vedelaar et al., "Lapatinib and 17AAG reduce ${ }^{89} \mathrm{Zr}$-trastuzumab-F( $\left.\mathrm{ab}^{\prime}\right)^{2}$ uptake in SKBR3 tumor xenografts," Molecular Pharmaceutics, vol. 9, no. 11, pp. 2995-3002, 2012.

[64] I. S. Moreira, P. A. Fernandes, and M. J. Ramos, "Vascular endothelial growth factor (VEGF) inhibition: a critical review," Anti-Cancer Agents in Medicinal Chemistry, vol. 7, no. 2, pp. 223-245, 2007.

[65] J. Lin and W. K. Kelly, "Targeting angiogenesis as a promising modality for the treatment of prostate cancer," Urologic Clinics of North America, vol. 39, no. 4, pp. 547-560, 2012.

[66] D. Maru, A. P. Venook, and L. M. Ellis, "Predictive biomarkers for bevacizumab: are we there yet?" Clinical Cancer Research, vol. 19, no. 11, pp. 2824-2827, 2013.

[67] M. T. Schweizer and M. A. Carducci, "From bevacizumab to tasquinimod: angiogenesis as a therapeutic target in prostate cancer," Cancer Journal, vol. 19, no. 1, pp. 99-106, 2013.

[68] A. Argiris, A. P. Kotsakis, T. Hoang et al., "Cetuximab and bevacizumab: preclinical data and phase II trial in recurrent or metastatic squamous cell carcinoma of the head and neck," Annals of Oncology, vol. 24, no. 1, pp. 220-225, 2013.

[69] J. A. Chan, K. Stuart, C. C. Earle et al., "Prospective study of bevacizumab plus temozolomide in patients with advanced neuroendocrine tumors," Journal of Clinical Oncology, vol. 30, no. 24, pp. 2963-2968, 2012.

[70] J. R. Kroep and J. W. Nortier, "The role of bevacizumab in advanced epithelial ovarian cancer," Current Pharmaceutical Design, vol. 18, no. 25, pp. 3775-3783, 2012.

[71] P. G. Morris, "Bevacizumab is an active agent for recurrent highgrade glioma, but do we need randomized controlled trials?" Anti-Cancer Drugs, vol. 23, no. 6, pp. 579-583, 2012.

[72] S. Sato and H. Itamochi, "Bevacizumab and ovarian cancer," Current Opinion in Obstetrics and Gynecology, vol. 24, no. 1, pp. 8-13, 2012.

[73] W. B. Nagengast, E. G. de Vries, G. A. Hospers et al., "In vivo VEGF imaging with radiolabeled bevacizumab in a human ovarian tumor xenograft," Journal of Nuclear Medicine, vol. 48, no. 8, pp. 1313-1319, 2007.

[74] W. B. Nagengast, M. A. de Korte, T. H. Oude Munnink et al., ${ }^{\star 89}$ Zr-bevacizumab PET of early antiangiogenic tumor response to treatment with HSP90 inhibitor NVP-AUY922," Journal of Nuclear Medicine, vol. 51, no. 5, pp. 761-767, 2010.

[75] A. R. van der Bilt, A. G. T. van Scheltinga, H. Timmer-Bosscha et al., "Measurement of tumor VEGF-A levels with ${ }^{89} \mathrm{Zr}$ bevacizumab PET as an early biomarker for the antiangiogenic effect of everolimus treatment in an ovarian cancer xenograft model," Clinical Cancer Research, vol. 18, no. 22, pp. 6306-6314, 2012.

[76] W. B. Nagengast, M. N. Lub-de Hooge, S. F. Oosting et al., "VEGF-PET imaging is a noninvasive biomarker showing differential changes in the tumor during sunitinib treatment," Cancer Research, vol. 71, no. 1, pp. 143-153, 2011.

[77] P. Carmeliet, L. Moons, A. Luttun et al., "Synergism between vascular endothelial growth factor and placental growth factor contributes to angiogenesis and plasma extravasation in pathological conditions," Nature Medicine, vol. 7, no. 5, pp. 575-583, 2001.
[78] J. M. Rakic, V. Lambert, L. Devy et al., "Placental growth factor, a member of the VEGF family, contributes to the development of choroidal neovascularization," Investigative Ophthalmology and Visual Science, vol. 44, no. 7, pp. 3186-3193, 2003.

[79] T. H. Oude Munnink, K. R. Tamas, M. N. Lub-de Hooge et al., "Placental growth factor (PlGF)-specific uptake in tumor microenvironment of ${ }^{89}$ Zr-labeled PlGF antibody RO5323441," Journal of Nuclear Medicine, vol. 54, no. 6, pp. 929-935, 2013.

[80] J. R. Osborne, N. H. Akhtar, S. Vallabhajosula, A. Anand, K. Deh, and S. T. Tagawa, "Prostate-specific membrane antigenbased imaging," Urologic Oncology, vol. 31, no. 2, pp. 144-154, 2013.

[81] Y. Zhang, Z. Guo, T. Du et al., "Prostate specific membrane antigen (PSMA): a novel modulator of p38 for proliferation, migration, and survival in prostate cancer cells," Prostate, vol. 73, no. 8, pp. 835-841, 2013.

[82] A. Afshar-Oromieh, A. Malcher, M. Eder et al., "PET imaging with a $\left[{ }^{68} \mathrm{Ga}\right.$ ]gallium-labelled PSMA ligand for the diagnosis of prostate cancer: biodistribution in humans and first evaluation of tumour lesions," European Journal of Nuclear Medicine and Molecular Imaging, vol. 40, no. 4, pp. 486-495, 2013.

[83] M. J. Manyak, "Indium-111 capromab pendetide in the management of recurrent prostate cancer," Expert Review of Anticancer Therapy, vol. 8, no. 2, pp. 175-181, 2008.

[84] A. Sugyo, A. B. Tsuji, H. Sudo et al., "Evaluation of ${ }^{89}$ Zr-labeled human anti-CD147 monoclonal antibody as a positron emission tomography probe in a mouse model of pancreatic cancer," PLoS ONE, vol. 8, no. 4, Article ID e61230, 2013.

[85] U. H. Weidle, W. Scheuer, D. Eggle, S. Klostermann, and H. Stockinger, "Cancer-related issues of CD147," Cancer Genomics and Proteomics, vol. 7, no. 3, pp. 157-169, 2010.

[86] S. Riethdorf, N. Reimers, V. Assmann et al., "High incidence of EMMPRIN expression in human tumors," International Journal of Cancer, vol. 119, no. 8, pp. 1800-1810, 2006.

[87] S. Zucker, M. Hymowitz, E. E. Rollo et al., "Tumorigenic potential of extracellular matrix metalloproteinase inducer," The American Journal of Pathology, vol. 158, no. 6, pp. 1921-1928, 2001.

[88] Z. N. Chen, L. Mi, J. Xu et al., "Targeting radioimmunotherapy of hepatocellular carcinoma with iodine (131I) metuximab injection: clinical phase I/II trials," International Journal of Radiation Oncology Biology Physics, vol. 65, no. 2, pp. 435-444, 2006.

[89] Z. Zhang, H. Bian, Q. Feng et al., "Biodistribution and localization of iodine-131-labeled Metuximab in patients with hepatocellular carcinoma," Cancer Biology and Therapy, vol. 5, no. 3, pp. 318-322, 2006.

[90] J. Xu, Z. Y. Shen, X. G. Chen et al., "A randomized controlled trial of licartin for preventing hepatoma recurrence after liver transplantation," Hepatology, vol. 45, no. 2, pp. 269-276, 2007.

[91] P. Swietach, A. Hulikova, R. D. Vaughan-Jones, and A. L. Harris, "New insights into the physiological role of carbonic anhydrase IX in tumour pH regulation," Oncogene, vol. 29, no. 50, pp. 6509-6521, 2010.

[92] B. A. W. Hoeben, J. H. A. M. Kaanders, G. M. Franssen et al., "PET of hypoxia with ${ }^{89} \mathrm{Zr}$-labeled cG250-F $\left(\mathrm{ab}^{\prime}\right)_{2}$ in head and neck tumors," Journal of Nuclear Medicine, vol. 51, no. 7, pp. 1076-1083, 2010.

[93] A. M. Stillebroer, G. M. Franssen, P. F. A. Mulders et al., "ImmunoPET imaging of renal cell carcinoma with 124I- and ${ }^{89} \mathrm{Zr}$ Labeled Anti-CAIX monoclonal antibody cG250 in mice," Cancer Biotherapy \& Radiopharmaceuticals, vol. 28, no. 7, pp. 510-515, 2013. 
[94] S. Heskamp, H. W. Van Laarhoven, J. D. Molkenboer-Kuenen et al., "ImmunoSPECT and immunoPET of IGF-1R expression with the radiolabeled antibody R1507 in a triple-negative breast cancer model," Journal of Nuclear Medicine, vol. 51, no. 10, pp. 1565-1572, 2010.

[95] E. M. Jagoda, L. Lang, V. Bhadrasetty et al., "Immuno-PET of the hepatocyte growth factor receptor met using the 1-armed antibody onartuzumab," Journal of Nuclear Medicine, vol. 53, no. 10, pp. 1592-1600, 2012.

[96] L. R. Perk, M. Stigter-van Walsum, G. W. Visser et al., "Quantitative PET imaging of Met-expressing human cancer xenografts with ${ }^{89} \mathrm{Zr}$-labelled monoclonal antibody DN30," European Journal of Nuclear Medicine and Molecular Imaging, vol. 35, no. 10, pp. 1857-1867, 2008.

[97] J. G. Sham, F. M. Kievit, J. R. Grierson et al., "Glypican3-targeted ${ }^{89} \mathrm{Zr}$ PET imaging of hepatocellular carcinoma," Journal of Nuclear Medicine, vol. 55, no. 5, pp. 799-804, 2014.

[98] J. L. Seitchik, J. C. Peeler, M. T. Taylor et al., "Genetically encoded tetrazine amino acid directs rapid site-specific in vivo bioorthogonal ligation with trans-cyclooctenes," Journal of the American Chemical Society, vol. 134, no. 6, pp. 2898-2901, 2012.

[99] P. K. Börjesson, Y. W. Jauw, R. Boellaard et al., "Performance of immuno-positron emission tomography with zirconium-89labeled chimeric monoclonal antibody U36 in the detection of lymph node metastases in head and neck cancer patients," Clinical Cancer Research, vol. 12, no. 7, part 1, pp. 2133-2140, 2006.

[100] S. N. Rizvi, O. J. Visser, M. J. W. Vosjan et al., "Biodistribution, radiation dosimetry and scouting of $90 \mathrm{Y}$ - ibritumomab tiuxetan therapy in patients with relapsed B-cell non-Hodgkin's lymphoma using ${ }^{89} \mathrm{Zr}$-ibritumomab tiuxetan and PET,' European Journal of Nuclear Medicine and Molecular Imaging, vol. 39, no. 3, pp. 512-520, 2012.

[101] E. C. Dijkers, T. H. Oude Munnink, J. G. Kosterink et al., "Biodistribution of ${ }^{89} \mathrm{Zr}$-trastuzumab and PET imaging of HER2positive lesions in patients with metastatic breast cancer," Clinical Pharmacology and Therapeutics, vol. 87, no. 5, pp. 586-592, 2010.

[102] R. Bruno, C. B. Washington, J. Lu, G. Lieberman, L. Banken, and P. Klein, "Population pharmacokinetics of trastuzumab in patients with HER2+ metastatic breast cancer," Cancer Chemotherapy and Pharmacology, vol. 56, no. 4, pp. 361-369, 2005.

[103] S. B. M. Gaykema, A. H. Brouwers, M. N. L. Hooge et al., " ${ }^{89} \mathrm{Zr}-$ bevacizumab PET imaging in primary breast cancer," Journal of Nuclear Medicine, vol. 54, no. 7, pp. 1014-1018, 2013.

[104] P. K. Börjesson, Y. W. Jauw, R. de Bree et al., "Radiation dosimetry of ${ }^{89} \mathrm{Zr}$-labeled chimeric monoclonal antibody U36 as used for immuno-PET in head and neck cancer patients," Journal of Nuclear Medicine, vol. 50, no. 11, pp. 1828-1836, 2009.

[105] W. C. Buijs, W. J. Oyen, E. T. Dams et al., "Dynamic distribution and dosimetric evaluation of human non-specific immunoglobulin G labelled with ${ }^{111}$ In or 99Tcm," Nuclear Medicine Communications, vol. 19, no. 8, pp. 743-751, 1998.

[106] A. G. T. Terwisscha van Scheltinga, G. M. van Dam, W. B. Nagengast et al., "Intraoperative near-infrared fluorescence tumor imaging with vascular endothelial growth factor and human epidermal growth factor receptor 2 targeting antibodies," Journal of Nuclear Medicine, vol. 52, no. 11, pp. 1778-1785, 2011.

[107] H. Hong, Y. Zhang, G. W. Severin et al., "Multimodality imaging of breast cancer experimental lung metastasis with bioluminescence and a monoclonal antibody dual-labeled with ${ }^{89} \mathrm{Zr}$ and
IRDye 800CW," Molecular Pharmaceutics, vol. 9, no. 8, pp. 23392349, 2012.

[108] Y. Zhang, H. Hong, G. W. Severin et al., "ImmunoPET and near-infrared fluorescence imaging of CD105 expression using a monoclonal antibody dual-labeled with ${ }^{89} \mathrm{Zr}$ and IRDye 800CW," American Journal of Translational Research, vol. 4, no. 3, pp. 333-346, 2012. 


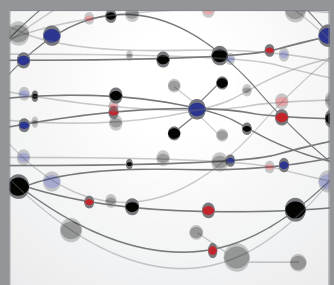

The Scientific World Journal
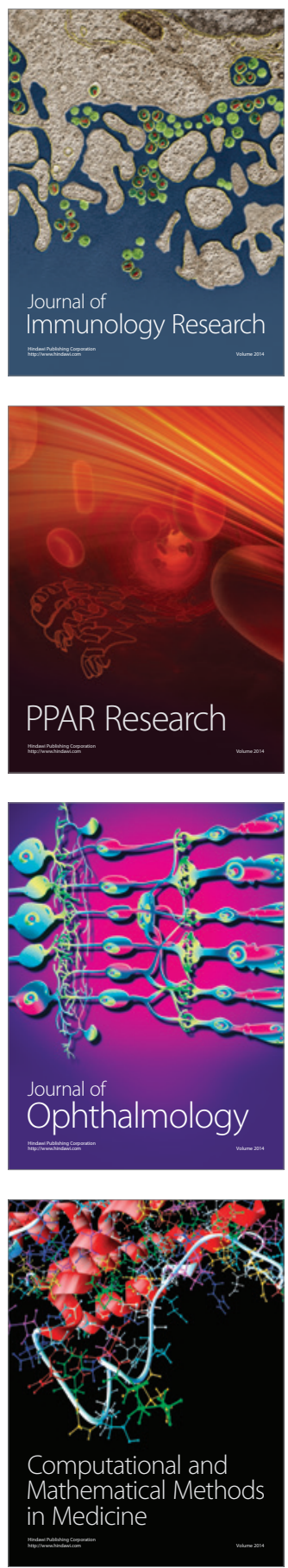

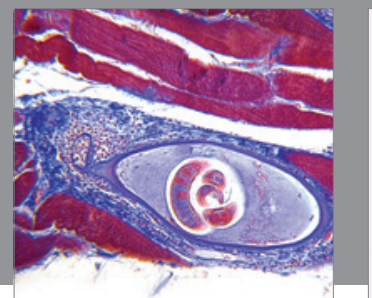

Gastroenterology

Research and Practice
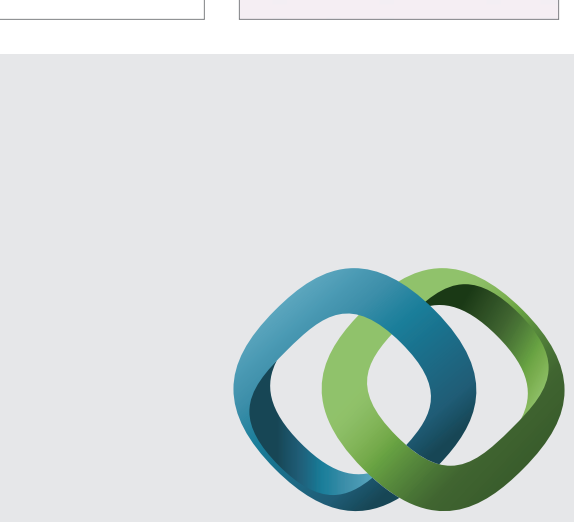

\section{Hindawi}

Submit your manuscripts at

http://www.hindawi.com
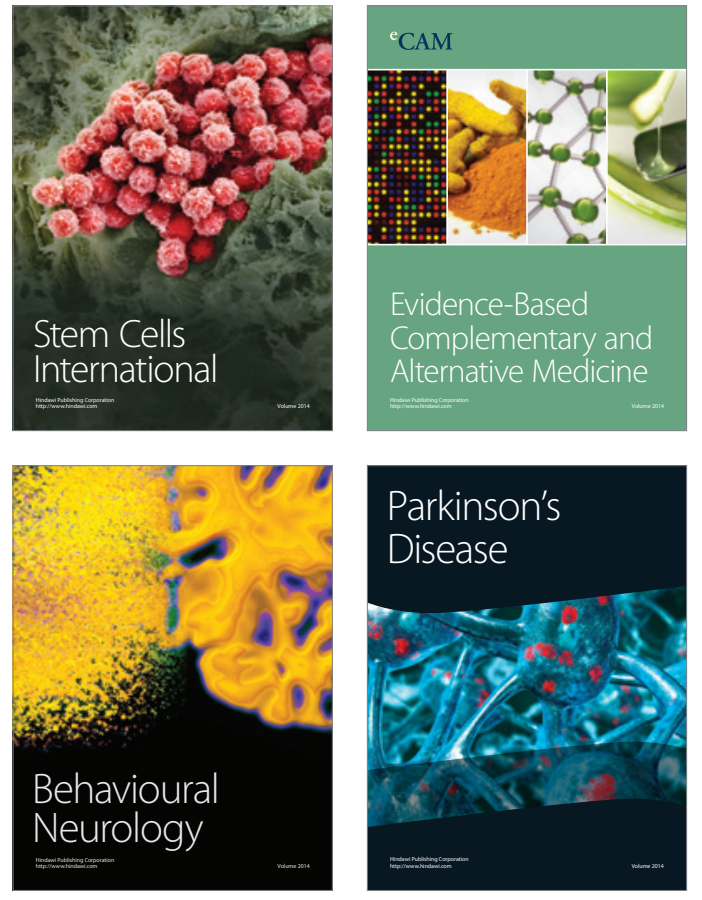
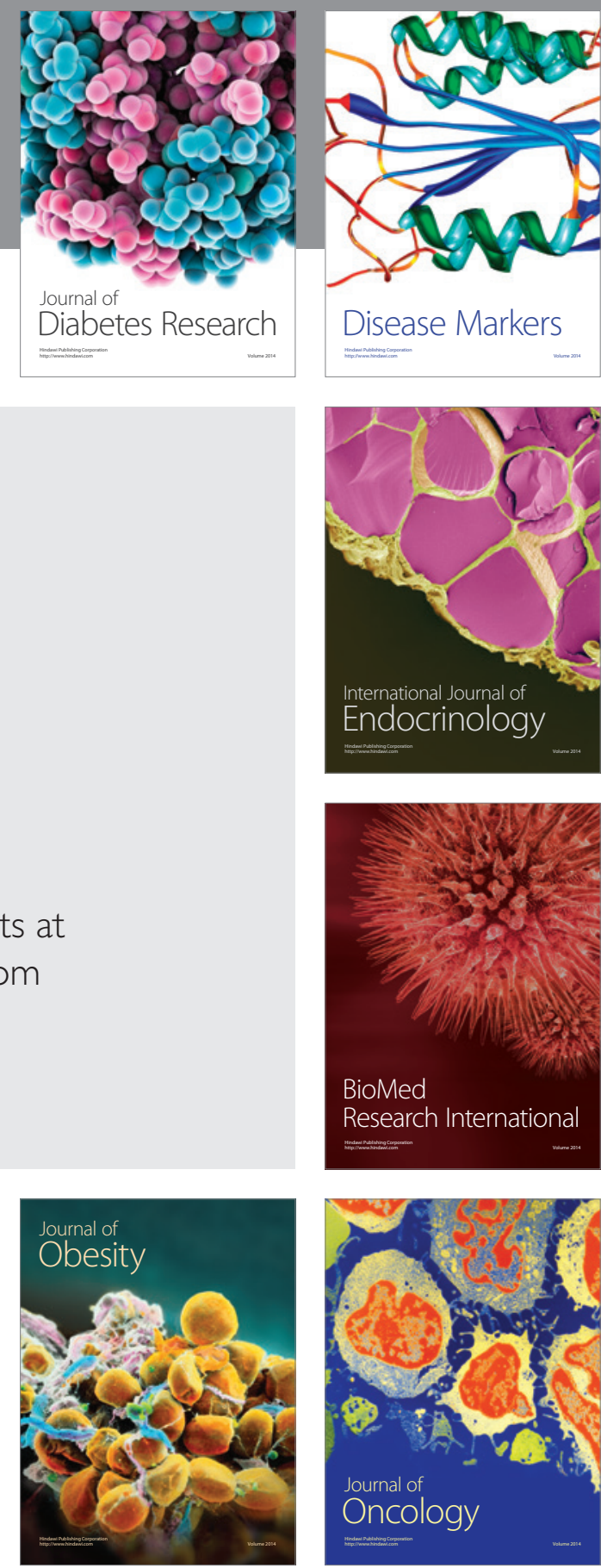

Disease Markers
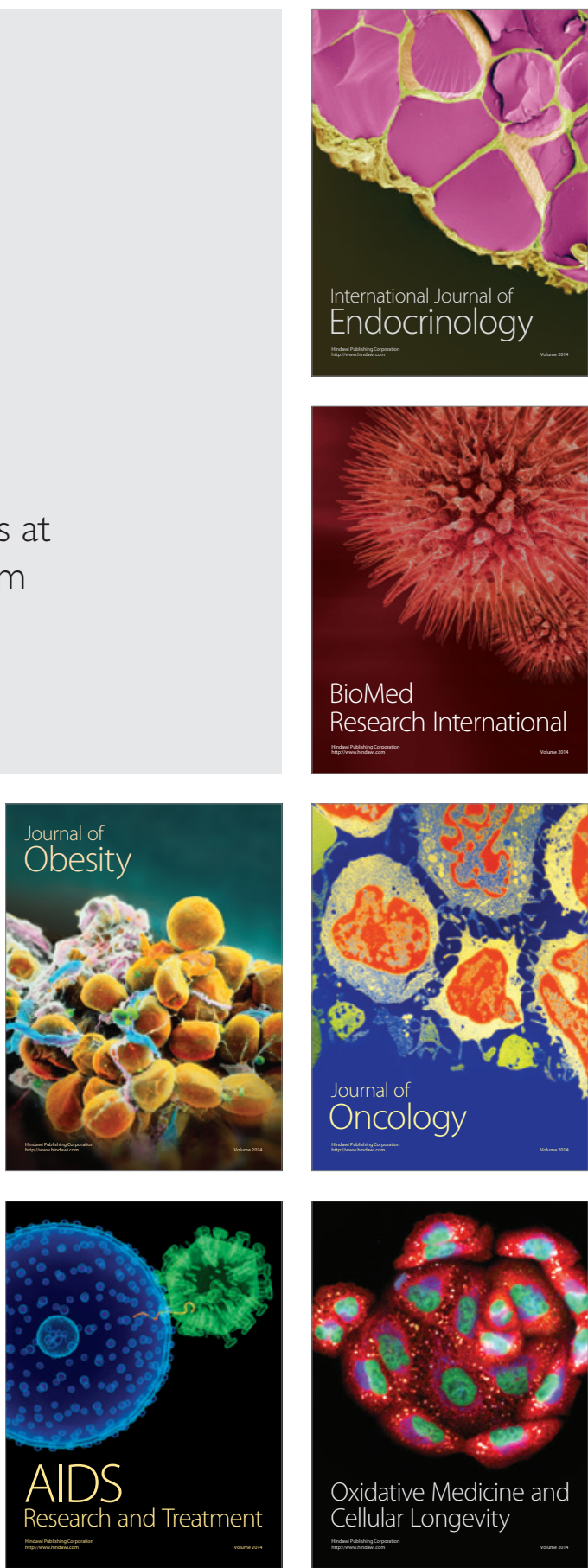